\title{
HYSTERESIS AND THE WELFARE EFFECT OF CORRECTIVE POLICIES: THEORY AND EVIDENCE FROM AN ENERGY-SAVING PROGRAM
}

\author{
Francisco Costa François Gerard
}

September 18, 2020

\begin{abstract}
This paper provides stark evidence of hysteresis - the failure of an effect to reverse itself as its underlying cause is reversed - in energy demand. We estimate that half of the $23 \%$ reduction in residential electricity use caused by a 9-month-long policy that was imposed on millions of Brazilians has persisted for at least 12 years. We examine the implications of our finding by extending the traditional welfare analysis of corrective policies to allow for hysteresis. Our estimate highlights that failing to take hysteresis into account could severely bias the welfare evaluation of policies aimed at reducing (long-run) energy demand.
\end{abstract}

In the presence of an externality, policies that change the behavior of private economic agents may be socially beneficial. For instance, environmental damages from energy use may justify a tax to reduce energy demand. Traditional policy analysis evaluates the welfare effect of such corrective policies by weighing the welfare gain from addressing the externality and the loss in private surplus due to the change in the behavior at stake. When doing so, it typically assumes away the possibility that a policy may affect choices persistently, even if it is no longer in place. In this paper, we study the importance of such "hysteresis" - the failure of an effect to reverse itself as its underlying cause is reversed (Dixit, 1989) - for the welfare evaluation of corrective policies.

We would like to thank four anonymous referees, Michael Best, Gharad Bryan, Robin Burgess, Lucas Davis, Joisa Dutra, Marina de Mello, Ben Faber, Claudio Ferraz, Fred Finan, Greg Fischer, Meredith Fowlie, Jason Garred, Gustavo Gonzaga, Michael Greenstone, Ryan Kellog, Gilat Levy, Jamie McCasland, Guy Michaels, Edward Miguel, Mushfiq Mobarak, Marcelo Moreira, Gerard Padró i Miquel, Joana Naritomi, Emmanuel Saez, Edson Severnini, Reinaldo Souza, Anna Spurlock, Eric Verhoogen, Catherine Wolfram, and seminar participants at many universities and conferences. Stéphanie Dinóa, Louise Guillouet, Tiago Lazier, Gustavo Macedo, John Pease, and Beatriz Rache provided outstanding research assistance. We also thank ANEEL, PROCEL, LIGHT, FAME, and Whirlpool for sharing important data. François Gerard benefited from the support of an Excellence Scholarship of Wallonie-Bruxelles International. This study was financed in part by CAPES/Brasil; Grant \#001. Francisco Costa, FGV EPGE, e-mail: francisco.costa@fgv.br. François Gerard, Queen Mary, University of London, e-mail: f.gerard@qmul.ac.uk. 
First, we provide stark evidence that hysteresis is a relevant phenomenon to consider in the context of energy demand. We estimate that about half of the dramatic short-run reductions in residential electricity use induced by a 9-month-long policy that was imposed on millions of Brazilians in 2001 has persisted for at least 12 years after the policy ended. Second, we extend the traditional public finance analysis of corrective policies to allow for hysteresis in household behaviors. We then use our empirical estimate to illustrate the implications that such hysteresis can have for the welfare evaluation of policies aimed at reducing energy demand in the short run or the long run.

Our application is well suited for studying hysteresis. The policy that we analyze led to the largest short-run reductions in residential electricity use among temporary energy-saving programs worldwide (Meier, 2005), and we can estimate its impact for more than 10 years after it ended. Moreover, most scenarios to mitigate climate change involve large reductions in electricity use by buildings (IPCC, 2014). Yet, because of low price elasticities, traditional policy analysis implies that inducing large long-run changes in residential energy use will lead to severe losses in consumer surplus, and may therefore not increase welfare despite sizable externalities.

In early 2001, electricity generation capacity was severely reduced in some regions of Brazil because of an exceptional and temporary drop in the streamflow level of the rivers that serve the hydroelectric power plants in these regions. To prevent generalized blackouts, the government adopted a temporary energy-saving program in affected areas that was aimed at reducing residential electricity use by $20 \%$. Households were only given a three-week advance notice and the policy was implemented between June 2001 and February 2002. During that period, households were assigned individual quotas and were subject to various incentives to consume less than their quota.

We estimate the short- and long-run effects of the policy through a difference-in-differences comparing distribution utilities subject to the policy to those that were exempt. We use administrative data on average residential electricity use for every distribution utility between 1991 and 2014. We confirm that the policy had a large short-run impact $(-23 \%) .{ }^{1}$ We then show that half of that impact has persisted in the long run $(-12 \%)$. This can be seen in the raw data in Figure 1. Our

\footnotetext{
${ }^{1}$ Maurer, Pereira and Rosenblatt (2005) document short-run changes in electricity use using aggregate data.
} 
Figure 1: Impact of the temporary energy-saving program on residential electricity use

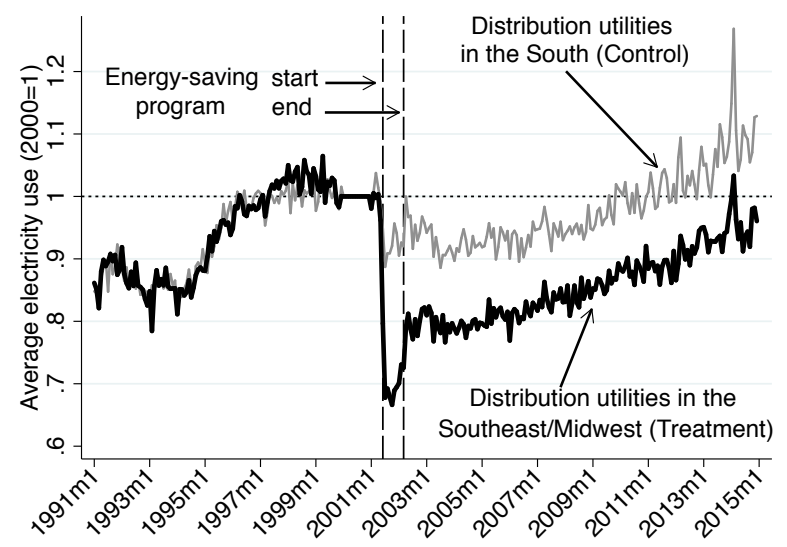

Notes: The figure presents the impact of the energy-saving program by comparing average residential electricity use per customer for distribution utilities in the Southeast/Midwest, which were subject to the policy, and for those in the South, which were exempt. It displays unweighted averages (using raw data) across distribution utilities in each month. Each average is normalized by its level in the same month in 2000 to net out the seasonality in electricity use.

estimates are robust to using different specifications and to controlling for a series of confounders, such as changes in prices, demographics, or income levels. Moreover, using synthetic control methods, we find negative long-run impacts for every distribution utility subject to the policy.

We complement these findings with evidence based on monthly longitudinal billing data from 2000 to 2005 for 3 million customers of one affected distribution utility. We show that the change in average electricity use at the level of the distribution utility came from large and persistent reductions by most customers throughout the electricity use distribution. Using idiosyncratic variation in quotas across customers, we also find that $36 \%-56 \%$ of the short-run effect induced by that variation during the crisis persisted in subsequent years. Finally, surveys suggest that an important mechanism of hysteresis was a change in the way households use their electrical appliances.

This evidence motivates the second part of the paper in which we examine how the possibility that a policy may alter choices persistently, even if it is no longer in place, affects the welfare evaluation of corrective policies. We lay out a two-period framework in which households' choices in period 1 may change their demand for electricity in period 2. We then show how such hysteresis affects the traditional public finance analysis of corrective policies. An advantage of using this approach is that it gives rise to welfare formulas that are invariant to the specific mechanisms 
of hysteresis (e.g., physical investments, learning), under a "revealed preference" condition that demand curves capture households' willingness-to-pay for electricity (Chetty, 2009).

First, we consider a short-run corrective policy (e.g., a quota or a tax) imposed in period 1 only. In absence of hysteresis, its welfare effect is the sum of a loss in consumer surplus, a loss in producer surplus, and a welfare gain from addressing potential externalities in period 1 . With hysteresis, however, the persistent reduction in electricity use also implies a welfare gain from addressing potential externalities in period 2, as well as a loss in producer surplus in that period. Second, we consider a long-run policy imposed in both periods. In that case, traditional policy analysis correctly accounts for the loss in producer surplus and for the correction of externalities in each period. The main novelty is that it would overestimate the loss in consumer surplus in period 2 in the presence of hysteresis. This is because part of the reduction in electricity use in period 2 would take place in absence of any policy in that period. We show that these implications of hysteresis are robust across a series of extension (e.g., allowing for social incentives) under the revealed preference condition. Yet, we also show that they can differ in important ways if we allow for behavioral considerations (e.g., if households are myopic about their own hysteresis).

The theory highlights that the persistent impact of the short-run policy, which is the theoretical framework's counterpart of our empirical estimate, becomes a key input to evaluate the welfare effect of both short-run and long-run policies in the presence of hysteresis. Thus, we end by using our estimate to illustrate the implications of taking hysteresis into account quantitatively. We first show that this would decrease the welfare evaluation of the short-run policy studied in the paper. The long-run welfare gain from the persistent reduction in electricity use has likely been sizable, but the long-run loss in producer surplus has likely been much larger, given the relatively high mark-up over private marginal cost in electricity markets (Borenstein and Bushnell, 2018). To illustrate the implications of hysteresis in the case of a long-run policy, we consider a hypothetical policy aimed at reducing electricity use by $23 \%$ from June 2001 to December 2014. By failing to take into account a persistent $12 \%$-impact due to the first 9 months of the policy, we show that one could overestimate the long-run loss in consumer surplus by $285 \%$. Therefore, if long-run 
corrective policies may lead to severe losses in consumer surplus for relatively inelastic behaviors, such as energy use, one may largely overestimate these losses by assuming away hysteresis.

This paper makes three main contributions. First, the empirical findings of this paper contribute directly to the growing body of research that estimates the persistent effect of short-run policies on a range of behaviors. ${ }^{2}$ Moreover, while existing papers usually evaluate the policy implications of their findings in terms of cost-effectiveness, we provide a framework to evaluate the implications of such findings for a welfare analysis. In so doing, we clarify that first-order considerations for cost-effectiveness - quantifying the role of mechanisms that do or do not involve monetary costs (e.g., physical investments vs. behavioral changes) - become secondary for a welfare analysis. In contrast, we show that other considerations - whether the persistent effect of a short-run policy is affected by policy expectations or behavioral biases - become first-order for a welfare analysis.

Second, the conceptual framework in this paper contributes to the literature on the economics of corrective policies more generally. Recent papers have extended the traditional policy analysis of corrective policies in several ways (e.g., Allcott and Taubinsky, 2015; Allcott and Kessler, 2019), but have not considered the role of hysteresis systematically. ${ }^{3}$ Our extension is not specific to the application in this paper or to a particular mechanism of hysteresis, so it can be used to guide the welfare evaluation of corrective policies in other settings where hysteresis is empirically relevant.

Third, this paper contributes to the economics literature on energy demand. Some papers provide evidence of hysteresis in this context, but they typically study shorter time horizons or the effects that they estimate dissipate over time (e.g., Reiss and White, 2008; Allcott and Rogers, 2014; Ito, 2015). Moreover, most of the growth in energy use comes from developing countries (IPCC, 2014), but the energy-saving potential of households in these countries remains understudied (see, e.g., Davis, Fuchs and Gertler, 2014, for an exception). Finally, our main conclusion that failing to take hysteresis into account may overestimate the long-run loss in consumer surplus -

\footnotetext{
${ }^{2}$ See, e.g., Charness and Gneezy (2009), Giné, Karlan and Zinman (2010), Ferraro and Price (2013), Bryan, Chowdhury and Mobarak (2014), Dupas (2014), Acland and Levy (2015), Fujiwara, Meng and Vogl (2016), Miller (2016), Brandon et al. (2017), Ito, Ida and Tanaka (2018) and Larcom, Rauch and Willems (2017).

${ }^{3}$ In recent theoretical work, Acemoglu et al. (2012) argue that temporary policies promoting greener technologies may have persistent effects on the supply side through directed technical change, and Hintermann and Lange (2013) investigate the dynamic optimal regulation of experience goods that generate environmental externalities.
} 
e.g., by $285 \%$ in our case - parallels recent findings that failing to account for adaptation may overestimate the damages from climate change (e.g., Barreca et al., 2016).

The paper proceeds as follows. Section 1 describes the empirical setting and our data. Section 2 presents our main results, Section 3 provides complementary evidence using microdata, and Section 4 discusses mechanisms. Section 5 examines the implications of taking hysteresis into account for the welfare evaluation of corrective policies. Section 6 concludes.

\section{Institutional background and data}

We start with an overview of the electricity distribution system in Brazil, of the causes of the 2001 electricity crisis, and of its energy-saving program. We then describe the data used in our analysis. More details on the institutional background and the data are provided in Appendix A.

\subsection{Institutional background}

A. Electricity distribution.- The Brazilian electricity system heavily relies on hydrological resources. In 2000 , hydropower was responsible for $81 \%$ of the production capacity and $94 \%$ of the electricity generation. The major national electricity system is divided into four subsystems: North (6.5\% of total load in 2000), Northeast (14.5\%), Southeast/Midwest (62\%), and South (17\%). Almost all households had access to the electricity grid in the South and the Southeast/Midwest in 2000, but not in the other two subsystems. More than 60 local monopolies (distribution utilities) distribute electricity to end consumers, and housing units are typically metered and billed separately every month. Finally, electricity prices are regulated by a federal agency (ANEEL). The main residential tariff is a flat unit price per kilowatt hour (kWh). An alternative tariff for lowincome and small consumers offers percentage discounts on the main tariff. Every four or five years, prices are revised to guarantee the economic viability of distribution utilities. However, yearly price adjustments only factor in changes in non-manageable costs, such as energy costs.

B. The 2001 electricity crisis. - The crisis was due to supply factors. It was caused by a his- 
Figure 2: Causes of the 2001 electricity crisis and of its temporary energy-saving program

(a) Stocked energy of the hydroelectric reservoirs

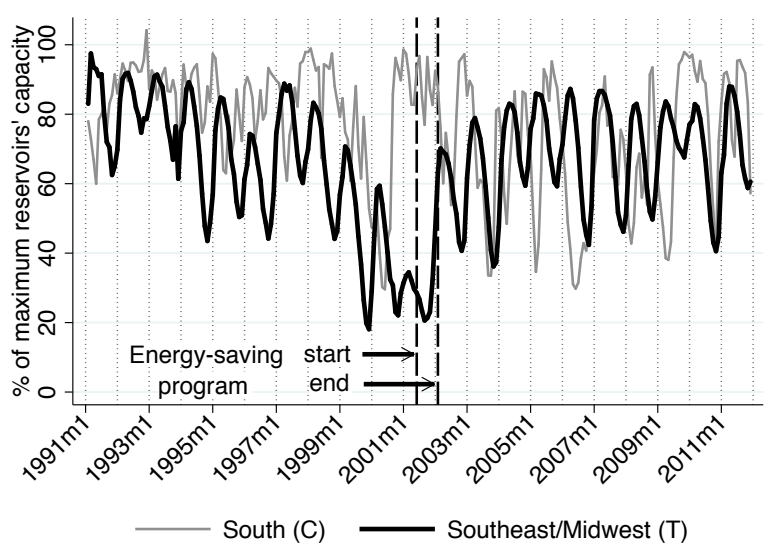

(b) Flow into the reservoirs (Southeast/Midwest)

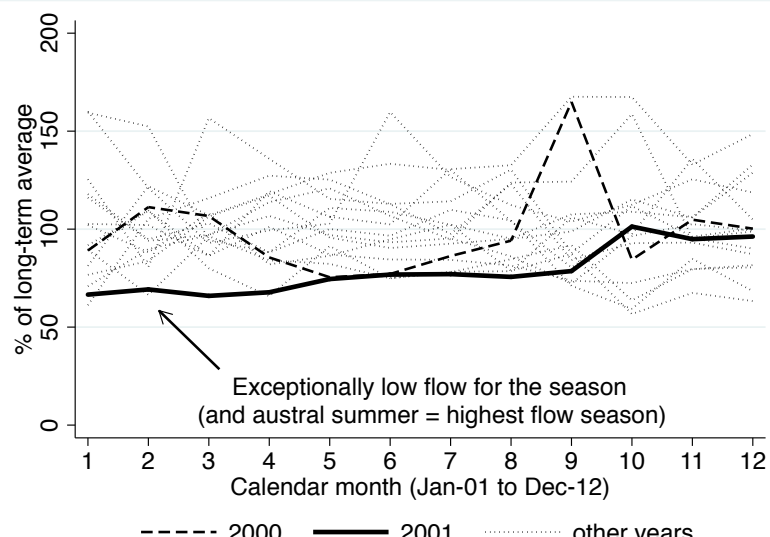

Notes: Panel (a) displays the evolution of the water level in the reservoirs of hydropower plants in the Southeast/Midwest and in the South in percentage of their maximum capacity; dotted lines indicate January in each year. Panel (b) displays the streamflow level of the rivers serving the reservoirs in the Southeast/Midwest in percentage of the long-term average streamflow levels in that month; each line corresponds to a specific year.

torically low streamflow in the rivers that serve hydropower plants in specific areas of the country. Figure 2a displays the evolution of the hydro-reservoirs' water level in the Southeast/Midwest and in the South. We focus on these two subsystems because of their similar development stage at the time. Water levels follow a seasonal pattern in the Southeast/Midwest, with heavy rain replenishing the reservoirs downstream during the austral summer. Levels were low in the two subsystems by 2000. In March 2001, in the Southeast/Midwest, levels reached their lowest point in 40 years (for the season) because of exceptionally low summer rainfall, and thus low flow into the reservoirs (see Figure 2b). In contrast, generous rain dissipated any risk of shortages in the South. The South could not transfer its excess supply to the other subsystems because of limited transmission capacity across subsystems. Moreover, while growth in demand had never outpaced growth in projected demand in the years prior to 2001, it outpaced growth in generation capacity. This was a nationwide issue, and it was later concluded that the South would have had a similar crisis if it had faced similar hydrological conditions as in the Southeast/Midwest (Kelman, 2001).

By April 2001, it was clear that electricity use had to decrease to avoid generalized blackouts. In May, the government announced that an incentive-based energy-saving program would start 
on June 4, although details remained unclear ( $O$ Globo, April 23, 2001). From the start, it was expected to last until February 2002 (the end of the next rainy season; Veja, July 19, 2001). Its goal was to reduce electricity use by $20 \%$ in the Southeast/Midwest; it was not implemented in the South. Figure 1 shows that households did not anticipate the energy-saving program by changing their electricity use prior to June 2001. As expected, the crisis ended in February 2002.

C. The energy-saving program. - The energy-saving program included several components. All customers were assigned an individual quota, typically equal to $80 \%$ of their average monthly electricity use from May to July 2000. Customers exceeding their quota were charged a fine per kWh consumed above $200 \mathrm{kWh}$ (resp. $500 \mathrm{kWh}$ ) equal to $50 \%$ (resp. 200\%) of the usual tariff. Fines thus targeted larger consumers. Customers who exceeded their quotas were also under the threat of power cuts of 3 to 6 days. Customers consuming less than their quota were eligible for a bonus per $\mathrm{kWh}$ reduced below their quota equal to at most $200 \%$ of the tariff. The bonus was guaranteed for customers consuming less than $100 \mathrm{kWh}$, but was to be paid out of the revenue from the fines otherwise. As a result, the quotas created customer-specific incentive schedules.

In practice, these components evolved over time and their implementation was not smooth. First, the program was so successful at reducing demand that fines did not raise enough money to pay out all bonuses, so a new guaranteed bonus for customers with quotas below $225 \mathrm{kWh}$ was introduced in September 2001. Second, distribution utilities did not have enough staff to implement power cuts, so they were limited to customers who repeatedly consumed far above their quota. Third, quotas were revised upward in December 2001 because the situation was improving.

Finally, an intensive information and conservation appeal campaign was carried throughout the crisis. For instance, daily television reports compared achievements to targets and often included stories of exemplary behavior, appeals to social preferences, and energy conservation advice. This may explain some spillovers to the South as the main media outlets are national in Brazil.

Other factors would not have affected electricity use in the Southeast/Midwest and in the South differentially. Tariff changes followed the usual regulatory framework during and after the crisis, and we find no differential change in the Southeast/Midwest if we replicate Figure 1 for electricity 
prices (see Appendix B). Some policies were implemented nationally and are thus part of our counterfactual. Finally, the summer rainfall in 2000-2001 was an outlier, so there was no rational reason for customers to differentially update their beliefs about the risk of future shortages.

\subsection{Data}

We use three main datasets. First, we use administrative data at the level of distribution utilities to estimate the overall impact of the energy-saving program. We use monthly data from mandatory reports to the regulatory agency (ANEEL) on total electricity consumption, revenues, and number of customers by category from 1991 to 2014. Our main outcome, average residential electricity use, is equal to the total residential consumption divided by the number of residential customers. We also compiled data from every tariff regulation from 1996 to 2014, so we have a balanced panel of average residential electricity use and residential electricity tariff at the monthly level for all distribution utilities. Additionally, we use decennial census data (2000 and 2010) and yearly data on population (1992-2014), GDP (1999-2012), formal employment (1996-2014), and average temperature (1996-2014) at the municipality level, which we match to utilities' concession area.

Second, we use longitudinal billing data at the customer level for one distribution utility in the Southeast to go beyond average effects and to estimate the short- and long-run impacts of variation in individual quotas. We obtained data for the universe of low-voltage customers of LIGHT, the distribution utility serving the Rio de Janeiro area, from January 2000 to December 2005. The data include more than three million residential customers, detail every component on electricity bills, and record metering and billing dates, meter location, and the quantity consumed in each month.

Third, we use household-level survey data (PPH surveys) conducted by the Electrical Energy Saving Program of the Brazilian government (PROCEL) to shed light on the mechanisms of hysteresis. Representative samples of customers from several utilities were surveyed before (19981999) and after (2004-2005) the crisis about their demographics, appliance ownership, and utiliza-

tion habits. In the second survey round, customers of distribution utilities that had been subject to the energy-saving program were also asked about their behaviors during and after the crisis. 


\section{The overall effect of the energy-saving program}

In this section, we estimate the average effect of the energy-saving program through a differencein-differences strategy, comparing distribution utilities in the Southeast/Midwest and in the South over time. We first motivate our approach. We then present the main results and robustness checks.

\subsection{Descriptive statistics supporting our empirical strategy}

Table 1 provides descriptive statistics supporting our identification assumption of a common trend in average residential electricity use for distribution utilities in the Southeast/Midwest and in the South. It also shows that this assumption is unlikely to hold, especially in the long run, for distribution utilities in the other two subsystems, which were also subject to the energy-saving program.

Columns (1)-(5) compare the mean and range of relevant variables in 2000 for distribution utilities in the four subsystems, and for LIGHT separately. Columns (6)-(8) compare the trend in these variables from 2000 to 2010 between distribution utilities in each subsystem and those in the South. Appendix B presents a similar table that includes the additional variables mentioned below.

We do not include distribution utilities in the North and the Northeast in our analysis for two main reasons. First, nearly all households had electricity prior to the crisis in the South, but not in the North and the Northeast. Moreover, the gap decreased by $8 \%-11 \%$ in the subsequent decade as the electricity grid continued to develop in these two subsystems. A common-trend assumption in average residential electricity use is unlikely to hold in this context. Second, households in the North and the Northeast were poorer and were less likely to own major electrical appliances in 2000. Strong poverty alleviation, as experienced in Brazil in the subsequent decade, can have very different effects on electricity use when initial ownership rates are so different (Wolfram, Shelef and Gertler, 2012). Accordingly, the ownership rate of refrigerators, which was lower in 2000, increased by $15 \%-26 \%$ in the North and the Northeast compared to the South between 2000 and 2010. This is unlikely a consequence of the crisis and thus violates a common-trend assumption.

In contrast, distribution utilities in the South constitute a more credible counterfactual for those 


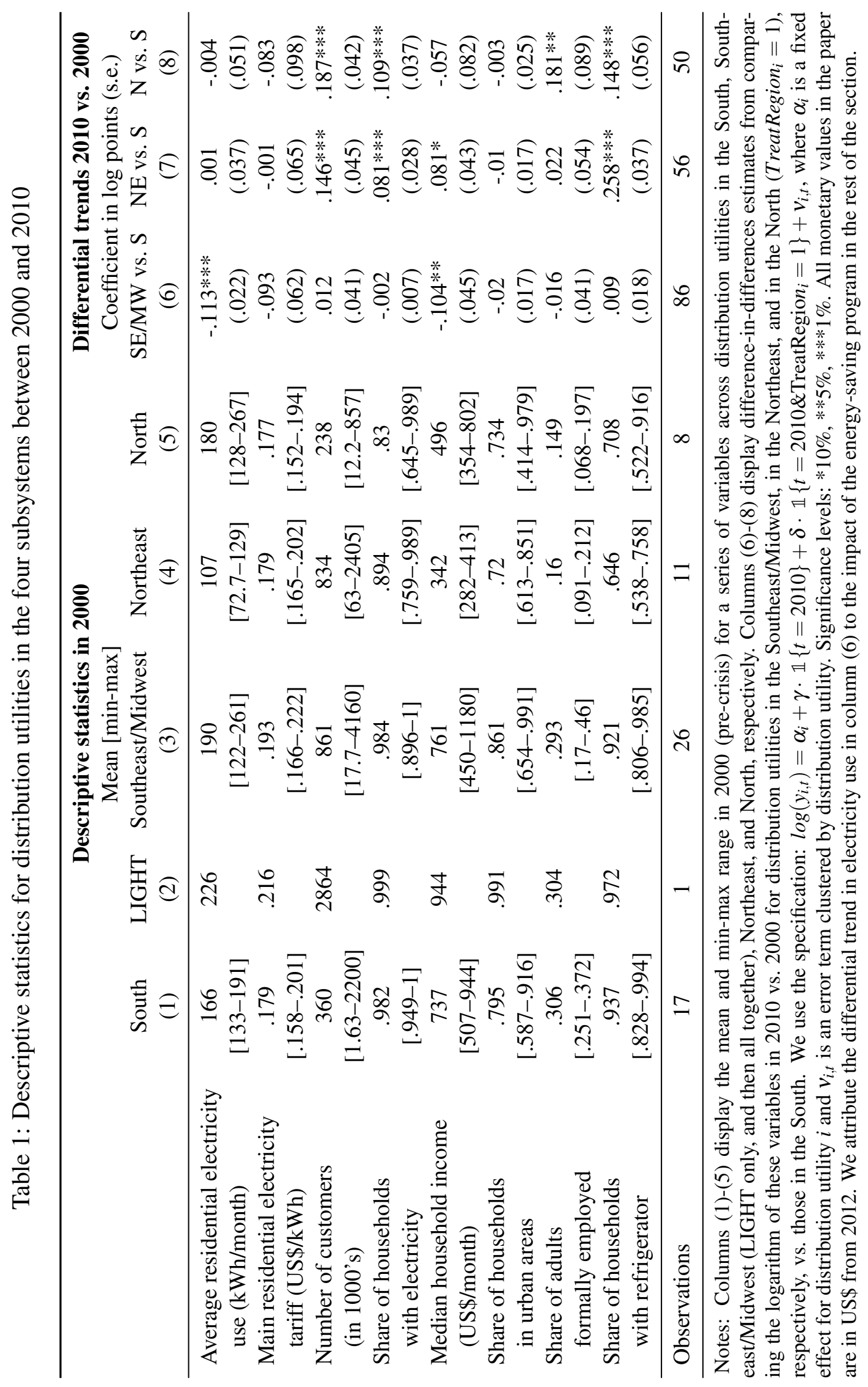


in the Southeast/Midwest. First, Figure 1 shows that distribution utilities in the two subsystems shared a common trend in average residential electricity use prior to the crisis. Second, nearly all households had electricity in 2000 in both subsystems, and customer bases evolved at a similar rate in the subsequent decade. Moreover, this does not hide any differential trend in urbanization, population size, household size, dwelling size, or dwelling characteristics. Third, electricity tariffs and ownership rates of major electrical appliances (refrigerator, washing machine, TV, air conditioner) were comparable in 2000, and also evolved at a similar rate in the subsequent decade.

Distribution utilities in the two subsystems differ in some respects. Average residential electricity use was higher in 2000 in the Southeast/Midwest, where median household income was higher (and average temperatures are always higher). Median household income also grew slower in the Southeast/Midwest afterward, although (formal) employment outcomes did not evolve differentially. Importantly, the range of initial values for these variables, and the changes in these values in subsequent years, overlapped for distribution utilities in the two subsystems (see Appendix B). Thus, we can control for relevant variables without purely relying on parametric assumptions.

In sum, the data appear to support our common-trend assumption, at least conditionally on controlling for some relevant factors. Additionally, as explained in Section 1, the timing of the crisis and the differential treatment between subsystems were entirely due to supply factors that were likely exogenous to potential changes in households' electricity use.

\subsection{Flexible specification and graphical presentation of the main results}

We begin by estimating the short- and long-run impact of the energy-saving program through a flexible difference-in-differences. We divide monthly observations into yearly periods before 2001 and after 2002, and in three periods for 2001 and 2002: pre-crisis (early 2001), crisis (June 2001February 2002), and post-crisis (rest of 2002). We then regress the logarithm of average residential electricity use $y_{i, t}$, for distribution utility $i$ in month $t$ (e.g., June 2001) using the specification:

$$
y_{i, t}=\alpha_{i}+\theta_{r, m}+\gamma_{p}+\delta_{p} \cdot \text { Treat }_{i} \cdot \mathbb{1}\left\{t \in \text { TimePeriod }_{p}\right\}+X_{i, t} \beta+v_{i, t} .
$$


The coefficients $\alpha_{i}, \gamma_{p}$, and $\theta_{r, m}$ are fixed effects for each distribution utility, each period, and each calendar month $m$ per subsystem $r$ (e.g., June in the Southeast/Midwest; to absorb seasonality effects), respectively. The coefficients $\delta_{p}$ estimate a differential effect in each period for distribution utilities in the Southeast/Midwest $\left(\right.$ Treat $\left._{i}=1\right)$ compared to those in the South $\left(\right.$ Treat $\left._{i}=0\right)$. Estimates of $\delta_{p}$ during and after the crisis capture the average treatment effect of the policy on the treated under a common-trend assumption. Estimates of $\delta_{p}$ in earlier periods test for a commontrend prior to the crisis. We reinforce the common-trend assumption by controlling for variables that may be correlated with other factors affecting electricity use. Specifically, we use the variables listed in Section 1.2 (in logs) that are available at the yearly level and can be matched to distribution utilities. Our preferred specification includes all these controls and is thus restricted to a balanced panel of utilities between 1999 and 2012 . We cluster the error term, $v_{i, t}$, by distribution utility. ${ }^{4}$

Figure 3: Treatment effect of the energy-saving program on average residential electricity use

(a) Difference-in-differences

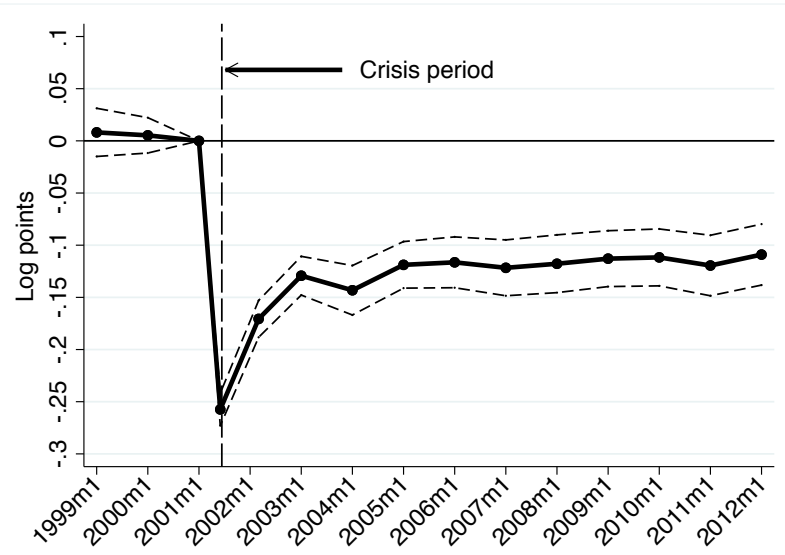

(b) Synthetic control methods

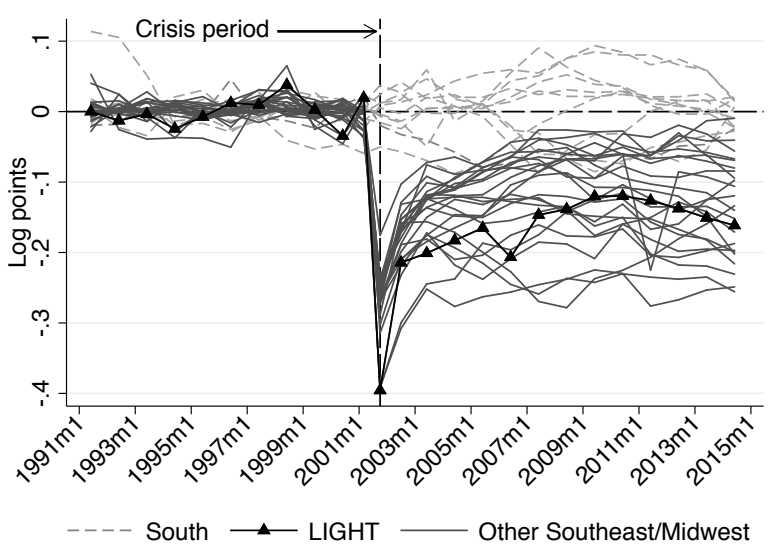

Notes: Panel ( $a$ ) displays the estimates of $\delta_{p}$ and their $95 \%$ confidence intervals based on the specification in equation (1) and using all the control variables $\left(X_{i, t}\right)$ available at the distribution utility level in each year. Panel $(b)$ displays the estimated effect for each distribution utility using synthetic control methods, as detailed in section 2.3. Darker and lighter lines correspond to distribution utilities in the Southeast/Midwest and in the South (placebo), respectively.

Figure 3a displays the estimates of $\delta_{p}$; the pre-crisis period (early 2001) is the reference period. Point estimates are close to 0 prior to the crisis, supporting our common-trend assumption. Average residential electricity use dropped by $-.26 \log$ points $(-23 \%)$ in the Southeast/Midwest compared

\footnotetext{
${ }^{4}$ The two subsystems cover large heterogeneous areas and electricity sector policy is centralized at the federal level.
} 
to the South when the energy-saving program came into effect. This is the first quasi-experimental estimate of the short-run effect for residential customers, but our main empirical result is that about half of that effect has persisted in the long run. Consumption levels partially rebounded after the crisis, but point estimates are stable from 2005 onward at about $-.12 \log$ points (-12\%).

\subsection{Summary of the main results and robustness checks}

A. Regression results. - The estimates in Figure 3a suggest that it is sufficient to divide observations into four time periods to describe our results: a pre-crisis period, a crisis period, a rebound post-crisis period until 2005, and a stable post-crisis period afterward. We thus adopt a sparser specification with these four periods to summarize and evaluate the robustness of our results:

$$
\begin{aligned}
& y_{i, t}=\alpha_{i}+\theta_{r, m}+\gamma_{t}+\delta_{S} \cdot \text { Treat }_{i} \cdot \text { Crisi }_{t}+\delta_{R} \cdot \text { Treat }_{i} \cdot \text { PostCrisisUntil2005 }_{t} \\
& +\delta_{L} \cdot \text { Treat }_{i} \cdot \text { PostCrisisAfter } 2005_{t}+X_{i, t} \beta+v_{i, t} \text {. }
\end{aligned}
$$

The coefficients $\gamma_{t}$ are now fixed effects for each month $t$. The coefficients $\delta_{S}, \delta_{R}$, and $\delta_{L}$ capture the average treatment effect of the policy on the treated in the short run (crisis months), in the rebound period (March 2002-December 2005), and in the long run (from January 2006 onward). The average difference in the months leading to the crisis is absorbed by the fixed effects $\alpha_{i}$.

Column (1) in Table 2 displays the estimated $\delta_{S}, \delta_{R}$, and $\delta_{L}$ for a specification that uses the same sample and set of covariates as for Figure 3a. Accordingly, the estimates are consistent with those in Figure 3a: average effects of $-.26 \log$ points $(-23 \%)$ during the crisis, $-.14 \log$ points $(-13 \%)$ in the rebound period, and $-.12 \log$ points $(-12 \%)$ in the stable post-crisis period after 2005 .

Columns (2)-(8) display similar results for variants of this specification. In column (2), we estimate a specification in levels instead of logarithms, for both the outcome and the covariates. The percentage effects correspond to $43 \mathrm{kWh}$ in the short run and $21 \mathrm{kWh}$ in the long run. Column (3) shows that results are unchanged when we exclude "outliers" from the Southeast/Midwest. ${ }^{5}$

\footnotetext{
${ }^{5}$ We exclude the eight distribution utilities with levels of key variables in 2000 (electricity use, main electricity tariff, and median household income) that fall outside the range of values observed in the South (see Table 1).
} 
Column (4) shows that results are slightly larger when we weight distribution utilities by their customer base in 2000. Column (5) shows that results are not driven by a particular season (e.g., the summer when consumption levels are higher): they are unchanged if we only include winter months. Column (7) shows that the results are similar if we use all years for which we can measure the outcome (1991-2014); we cannot include the set of covariates $\left(X_{i, t}\right)$ in this specification. ${ }^{6}$

Additionally, in columns (6) and (8), we use another specification to test whether the energysaving program caused not only level shifts but also trend breaks (Greenstone and Hanna, 2014):

$$
\begin{aligned}
& y_{i, t}=\alpha_{i}+\theta_{r, m}+\gamma_{t}+\kappa_{B} \cdot \text { Treat }_{i} \cdot \text { BeforeCrisis }_{t} \cdot t_{B}+\delta_{S} \cdot \text { Treat }_{i} \cdot \text { Crisis }_{t}+\kappa_{S} \cdot \text { Treat }_{i} \cdot \text { Crisi }_{t} \cdot t_{S} \\
& +\delta_{R} \cdot \text { Treat }_{i} \cdot \text { PostCrisisUntil2005 }_{t}+\kappa_{R} \cdot \text { Treat }_{i} \cdot \text { PostCrisisUntil2005 }_{t} \cdot t_{R}
\end{aligned}
$$

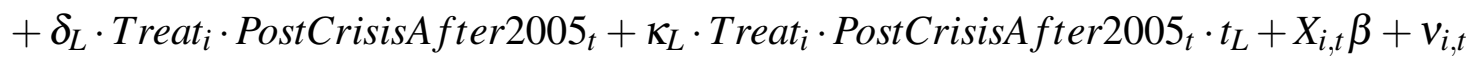

The linear trends $\left(t_{B}, t_{S}, t_{R}, t_{L}\right)$ are normalized to the start of their respective period, such that the coefficients $\delta_{S}, \delta_{R}$, and $\delta_{L}$ now estimate the average difference-in-differences (i.e., they capture level shifts) at the start of each period. The coefficients $\kappa_{B}, \kappa_{S}, \kappa_{R}$, and $\kappa_{L}$ test for a differential trend (i.e., they capture trend breaks) in treated distribution utilities in each of the periods, respectively.

Columns (6) and (8) display results that compare to those in columns (1) and (7), respectively. We find no evidence of a differential trend pre-crisis. During the crisis, the level shift is slightly less negative than the average effect because we estimate a negative trend break. Thus, the treatment effect was not fading away during the crisis. In the rebound period, the level shift is slightly more negative than the average effect because we find a positive trend break. We find no evidence of a differential trend after 2005, showing again that our estimated long-run effect is stable over time. ${ }^{7}$

B. Synthetic control results. - Finally, we estimate treatment effects for each distribution utility

\footnotetext{
${ }^{6}$ The number of distribution utilities is slightly smaller because a few distribution utilities were split after 1991. In Appendix B, we also show that the estimated long-term effect is robust to controlling for covariates that are not available at the yearly level but are available in the 2000 and the 2010 censuses (e.g., median household income, share of households living in urban areas, average household sizes). Moreover, we graphically show that long-term changes in consumption levels are systematically lower for distribution utilities in the Southeast/Midwest than in the South for given baseline levels or long-term changes in all the variables in Table 1 and in its continuation table in Appendix B.

${ }^{7}$ The last row in columns (6) and (8) also provides estimates of the 10-year effect of the short-run policy based on the estimated level shift and trend break in the stable period post-crisis.
} 
using synthetic control methods to show that our estimates of average effects are not driven by a few distribution utilities. Our estimator is the difference between the logarithm of average residential electricity use (demeaned and seasonally adjusted) in a treated distribution utility and in a weighted average of the control distribution utilities. Figure $3 b$ displays the results. Monthly estimates are averaged into time periods similar to those in Figure 3a, but we use all years from 1991 to 2014. Darker lines display estimates for treatment distribution utilities. Lighter lines display placebo estimates in which we compare each control distribution utility to a weighted average of the other ones. The synthetic controls closely match trends pre-crisis. The estimated short-run effect is large for all treated distribution utilities. The long-run effect is negative for all of them. Both the median and the average of these effects are equal to $-.14 \log$ points $(-13 \%)$ in 2014 ; the effect for LIGHT (the distribution utility for which we have microdata) is equal to -.16 log points $(-15 \%)$ in that year. In contrast, the median and the average for placebo estimates are around 0 in all years. ${ }^{8}$

In sum, a 9-month intervention led to a persistent reduction in residential electricity use by about $12 \%$ until 12 years after it ended, and potentially well beyond, as the long-run effect appears to be stable. To give an order of magnitude, this amounts to a reduction of 105.2 billion $\mathrm{kWh}$ in the Southeast/Midwest between March 2002 and December 2014 or 160\% of the reported electricity savings from the energy-efficiency programs of the Brazilian government over that period. ${ }^{9}$

\section{Evidence using the household-level billing data}

We now use the microdata from LIGHT to go beyond the average effect of the overall energysaving program. First, we analyze the anatomy of the persistent reduction in residential electricity use. Second, we exploit quasi-experimental variation in consumption quotas across customers during the crisis to provide evidence of hysteresis at the household level.

\footnotetext{
${ }^{8} \mathrm{We}$ show results from a similar exercise for the main electricity tariff in Appendix B. In that case, the range of estimated effects completely overlaps and centers around 0 for distribution utilities in the two subsystems.

${ }^{9}$ Our figure is calculated as: $\sum_{t} .12 \cdot \frac{x_{t}}{1-.12}$, where $x_{t}$ is the monthly residential consumption in the Southeast/Midwest. See PROCEL annual reports (procelinfo.com.br) for the government figure (66.5 billion kWh).
} 


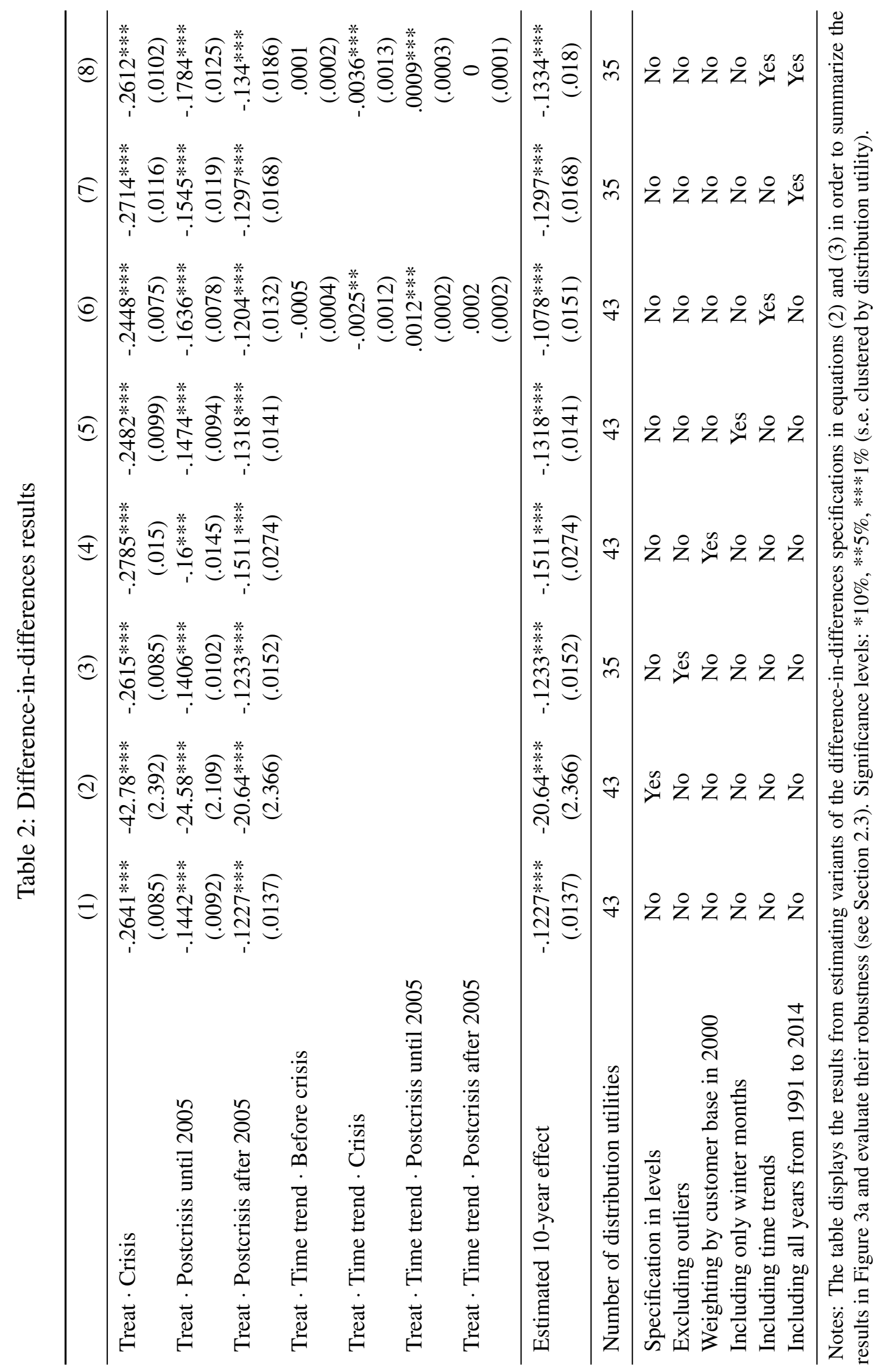




\subsection{Anatomy of the reduction in residential electricity use}

A. Validating the utility-level data and ruling out composition effects. - Figure 4a displays the average residential electricity use in the aggregate LIGHT data used in the previous section and in the microdata, in each month between 2001 and 2005 compared to the same month in 2000. It shows that the changes in average residential electricity use during and after the crisis are similar in the two datasets. This indicates that the aggregate data reported to the regulator are consistent with the metering data, which supports our use of these aggregate data in Section 2.

A limitation of utility-level data is that they could confound changes in household electricity use and composition changes in the customer base of distribution utilities (Levinson, 2014). However, Figure 4a shows that changes in average electricity use are also similar if we restrict attention to the balanced panel of customers metered regularly between 2000 and 2005. Composition effects, which are absent from that sample by construction, are thus unlikely to drive our results. ${ }^{10}$

B. Changes in the distribution of electricity use.- Figure $4 \mathrm{~b}$ displays kernel densities for average monthly electricity use before, during, and after the crisis for the same balanced panel. The density during the crisis is first-order stochastically dominated by the other ones; densities 1 year and 4 years after the crisis fall between the crisis and pre-crisis densities. The short- and long-run changes in average electricity use thus came from sizable reductions at every level of consumption.

C. Distribution of changes at given quota levels. - Figure 4c displays the distribution of changes in electricity use during and after the crisis, compared to before the crisis, for the subset of the balanced sample with a quota around $300 \mathrm{kWh}$. We consider customers with similar quotas and a relatively high baseline consumption (around 300/.8 =375 kWh) because their economic incentives were similar and simpler, i.e., they faced mostly fines for exceeding their quota. During the crisis, $98 \%$ of these customers reduced electricity use below their pre-crisis level, for a median change of $-34 \%$. Moreover, $91 \%$ reduced consumption below their quota, for a median change of $-22 \%$ below the quota (see Appendix C). That these customers consumed well below

\footnotetext{
${ }^{10}$ This also rules out any important role for households canceling their legal connection and instead stealing electricity, as such households would be excluded from the balanced panel. The available data to study electricity theft are very limited, but we provide additional evidence against any major role played by electricity theft in Appendix C.
} 
Figure 4: Anatomy of the reduction in residential electricity use

(a) Comparing changes in average residential electricity use in the utility-level data and in the microdata

(b) Distribution of average monthly electricity use over time for a balanced panel of customers
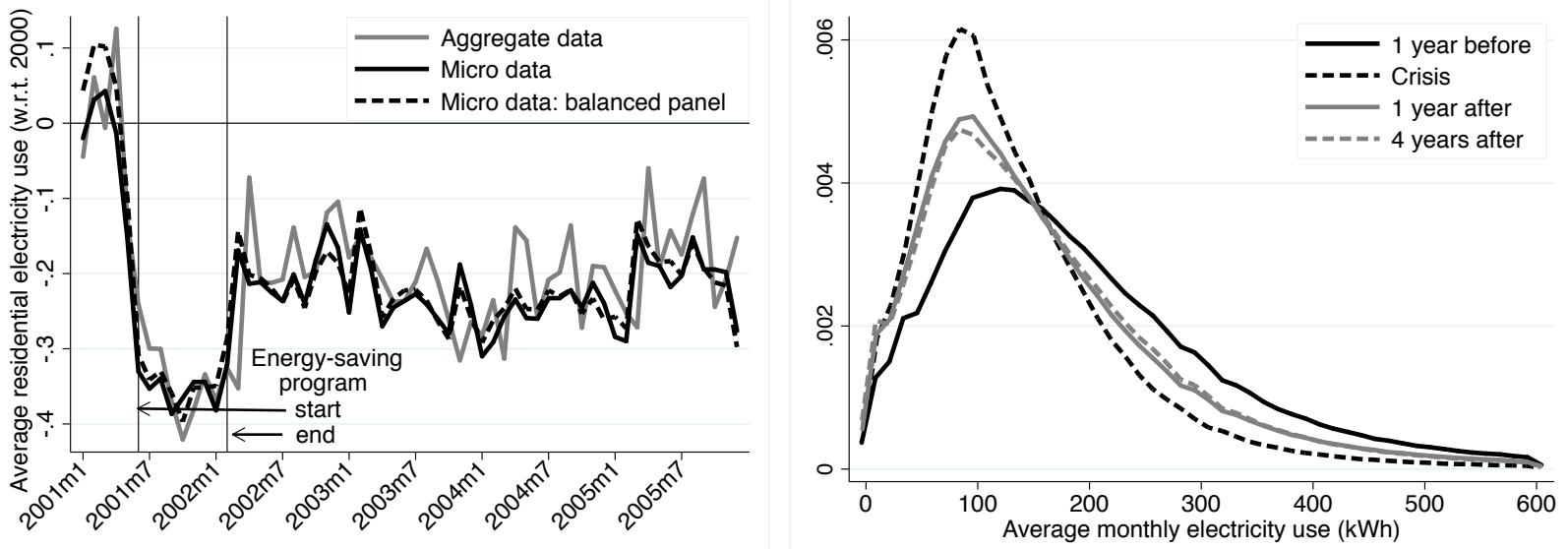

(c) Distribution of changes in average monthly electricity

(d) Correlation between changes in electricity use during use for a balanced panel of customers with similar quotas

and after the crisis for the sample used in panel (c)
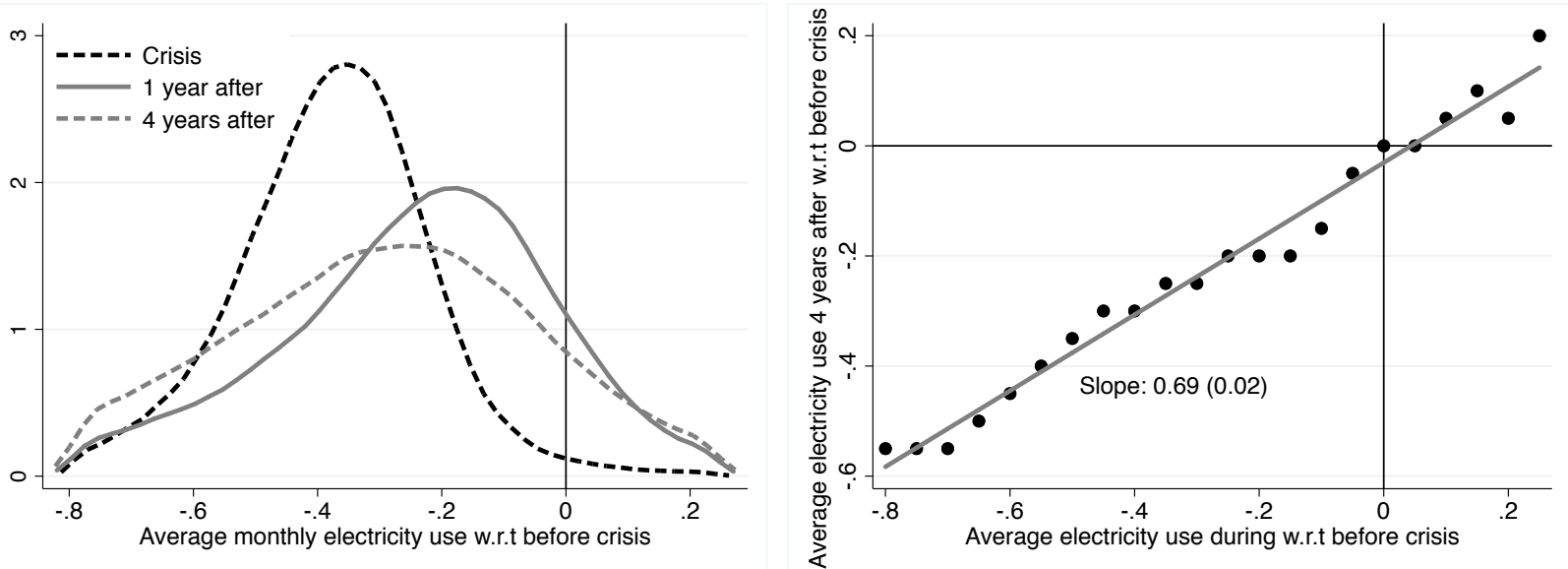

Notes: Panel ( $a$ ) displays the average electricity use for LIGHT customers in each month, compared to the same month in 2000, using the utility-level data, the microdata, and the balanced panel of customers metered regularly from 2000 to 2005 in the microdata (1,185,146 customers). Panel $(b)$ displays kernel densities for average monthly electricity use before, during, and after the crisis in this balanced panel. Panel (c) displays the distribution of changes in electricity use during and after the crisis, compared to the same months before the crisis, for a subset of the balanced sample in which customers had similar quotas (10\% above and below $300 \mathrm{kWh} / \mathrm{month} ; 83,966$ customers). Panel (d) displays the correlation between individual changes in electricity use during and after the crisis compared to the same months before the crisis, for the sample used in panel (c). Customers are averaged by bins of 5\% changes in electricity use during the crisis. The samples in panels (b)-(d) use data from July to December such that we can compare consumption levels up to four years after the crisis. Kernel densities use Epanechnikov kernels and optimal bandwidths. We present similar graphs as in panels (c) and (d) for other quota levels in Appendix C. 
their quota suggests that social incentives played a role, as they had no other incentive to further reduce consumption once complying with their quota. Four years after the crisis, $78 \%$ were still using less electricity than before the crisis; the median customer was using $22 \%$ less electricity. ${ }^{11}$

D. Persistence of household-level changes in electricity use during the crisis. - Figure 4d displays the correlation between individual short-run changes in electricity use during the crisis and long-run changes 4 years after the crisis (compared to before the crisis) for the same balanced sample used in Figure 4c. The strong correlation (.69) provides some first household-level evidence that changes in electricity use that took place during the crisis were very persistent.

\subsection{Evidence using quasi-experimental variation in consumption quotas}

The correlation in Figure 4d may overstate the household-level hysteresis in electricity use caused by the energy-saving program because part of the short-run changes in electricity use may come from other factors, such as mean reversion. In this subsection, we therefore use quasi-experimental variation in consumption quotas to isolate short-run changes in electricity due to the energy-saving program and provide causal evidence of hysteresis in electricity use at the household level.

A. Source of quasi-experimental variation in consumption quotas. - The monthly quota was set at $80 \%$ of the average monthly consumption between May and July 2000 for the typical household. However, it was set at $80 \%$ of the average consumption in their first three billing months for those households that moved into their housing unit ("movers") after May 2000. Because of strong seasonality in electricity use in Rio de Janeiro, these rules created variation in quotas among movers entirely because of differences in moving dates (measured by the date of their first electricity bill).

Figure 5a displays the average consumption in each month between March 2000 and February 2001 for the overall balanced panel of customers used above, and for the top quartile of the distribution in this sample. Consumption levels are higher in the austral summer and lower in the austral winter. The difference reaches more than $60 \%$ in the top quartile of the distribution, indicating that the seasonality in electricity use is particularly strong among large consumers. Figure

\footnotetext{
${ }^{11}$ These figures are only slightly smaller in the overall balanced panel (see Appendix C).
} 
Figure 5: Seasonality in residential electricity use and variation in quotas among movers

(a) Seasonality in residential electricity use and average quota of movers by moving month

(b) Distribution of quotas for winter (May 2000-Jul

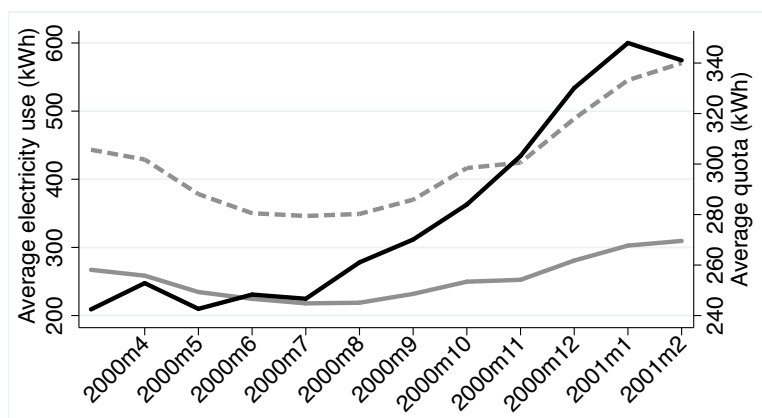
2000) and summer movers (Dec 2000-Feb 2001)
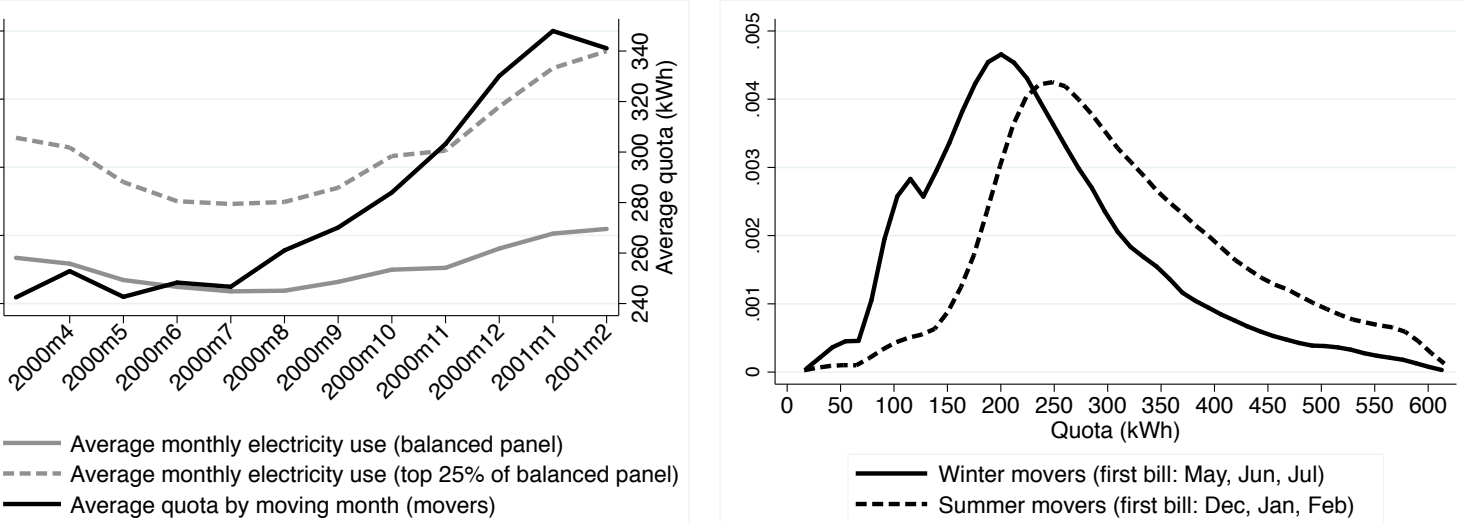

Notes: Panel (a) displays the average monthly consumption between March 2000 and February 2001 for the overall balanced panel of customers used in Figures $4 \mathrm{a}$ and $4 \mathrm{~b}$, and for the top quartile of the distribution in this sample. It also displays the average quota of customers who moved into their housing unit ("movers") in each of these months. The movers' sample is restricted to large consumers (see text) observed at least until December 2002 (66,037 customers). Panel (b) displays the quota distribution for those who moved in the winter (May-July; 13,557 customers) and in the summer (December-February; 11,725 customers). Kernel densities use Epanechnikov kernels and optimal bandwidths.

5a also displays the average quota of customers who moved into their housing unit in each of these months to show the impact of this seasonality on the movers' quotas. The sample is restricted to large consumers given the stronger seasonality in their electricity use. ${ }^{12}$ Customers who moved into their housing unit before May 2000, whose quota was based on the typical baseline period, had similar average quotas. In contrast, the quota of customers who moved in after May 2000 closely follows the seasonality. As a result, Figure $5 \mathrm{~b}$ shows that the quota distribution for summer movers first-order stochastically dominates the distribution for winter movers; at the median, the difference reaches $32 \%$, which is equivalent to offering a non-binding quota to summer movers.

B. Empirical strategy. - We exploit the variation from differences in moving dates to estimate the causal effect of the quotas on electricity use during and after the crisis. We use the following

\footnotetext{
${ }^{12}$ Our sample here and for the results in Table 3 includes customers who moved in between March 2000 (to make sure that they did not receive bills in earlier months) and February 2001 (to have at least three billing months prior to the crisis), and whose average consumption in March-May 2001 was in the top quartile of the distribution.
} 
specification in different periods for household $i$ that moved in neighborhood $n$ in week $t$ :

$$
y_{i, n, t}=\alpha_{n}+\beta \cdot \overline{\text { Quota }}_{t}^{-i}+v_{i, n, t}
$$

where $\alpha_{n}$ is a neighborhood fixed effect, and $y_{i, n, t}$ is the logarithm of the household $i$ 's quota ("firststage") or the logarithm of its average monthly electricity use in a given period ("reduced-form"). The variable $\overline{\text { uota }}_{t}^{-i}$ captures the variation in quotas from differences in moving dates. It is the logarithm of the average of the quota of all movers (excluding $i$ ) who received their first bill in the same week as household $i$ (we cluster standard errors by moving week). Figure 5 shows that the first stage is likely strong. Below, we present evidence that supports our exclusion restriction that the average quota of same-week movers does not directly affect households' consumption levels. ${ }^{13}$ C. Results. - Table 3 presents results for both mean and median effects. ${ }^{14}$ Column (1) shows that the average quota of same-week movers is positively correlated with movers' own quota. This first-stage coefficient is 0.79 and 0.66 for the mean effect and the median effect, respectively. Column (2) shows that the average quota of same-week movers does not predict differences in consumption levels before the crisis, however. This evidence supports our exclusion restriction. ${ }^{15}$

The next columns show that the average quota of same-week movers is positively correlated with consumption levels during and after the crisis, which we interpret as evidence of a causal effect of the quota. In column (3), we estimate that a $10 \%$ increase in the quota of same-week movers increased electricity use during the crisis by $1.37 \%$ for the mean and $1.15 \%$ for the median. The effect is precise, but it is not very large. This finding is consistent with the evidence that customers tended to reduce consumption well below their quota. Our estimates increase to $1.38 \%$ for the mean and $1.53 \%$ for the median when we control for the logarithm of pre-crisis consumption

\footnotetext{
${ }^{13}$ To be able to study long-term effects, we focus on movers metered regularly until the end of 2005 for the results in Table 3 (38,207 customers). Estimates of short-run effects are similar without this restriction (see Appendix C).

${ }^{14}$ Economic incentives were simpler for the median household in each moving week. Indeed, Figure 5b shows that the median quota was large enough (even for winter movers) such that the movers in our sample were mostly faced with fines for exceeding their quota. Quantile regressions do not include neighborhood effects because estimators would be inconsistent, and standard errors are obtained from performing 1,000 bootstrap replications.

${ }^{15}$ We also present placebo estimates in Appendix C using customers who moved into their housing units in similar calendar months but in the years after the crisis. The average consumption of same-week movers in their first three billing months does not predict differences in consumption levels in subsequent periods for these samples.
} 
Table 3: Impact of quasi-experimental variation in quotas on electricity use among movers

\begin{tabular}{cccccc} 
Log Quota & Log Consumption & \multicolumn{4}{c}{ Log Consumption July-December } \\
& March-May 2001 & 2001 & 2001 & 2002 & $2003-2005$ \\
(1) & $(2)$ & $(3)$ & (4) & $(5)$ & $(6)$
\end{tabular}

\begin{tabular}{|c|c|c|c|c|c|c|}
\hline $\begin{array}{l}\text { A. OLS regressions } \\
\text { Log Moving-Week Quota }\end{array}$ & $\begin{array}{c}.785 * * * \\
(.223)\end{array}$ & $\begin{array}{c}.000 \\
(.023)\end{array}$ & $\begin{array}{c}.137 * * * \\
(.034)\end{array}$ & $\begin{array}{c}.138 * * * \\
(.039)\end{array}$ & $\begin{array}{c}.087 * * * \\
(.024)\end{array}$ & $\begin{array}{l}.049 * * \\
(.024)\end{array}$ \\
\hline \multicolumn{7}{|c|}{ B. Quantile regressions (median) } \\
\hline Log Moving-Week Quota & $\begin{array}{c}.662 * * * \\
(.028)\end{array}$ & $\begin{array}{c}.018 \\
(.023)\end{array}$ & $\begin{array}{c}.115^{* * * *} \\
(.02)\end{array}$ & $\begin{array}{c}.153^{* * * *} \\
(.013)\end{array}$ & $\begin{array}{c}.087 * * * \\
(.023)\end{array}$ & $\begin{array}{c}.086^{* * * *} \\
(.013)\end{array}$ \\
\hline Observations & 38,207 & 38,207 & 38,207 & 38,207 & 38,207 & 114,621 \\
\hline Log Cons. March-May 2001 & No & No & No & Yes & Yes & Yes \\
\hline Year fixed effects & No & No & No & No & No & Yes \\
\hline
\end{tabular}

Notes: The table displays the results from estimating the specification in equation (4) for the outcome variables listed above each column. In columns (3)-(6), we use data from July to December to be able to compare consumption levels up to four years after the crisis. "Moving-Week Quota" is the average of the quota of all movers (excluding $i$ ) who received their first bill in the same week as household $i$. Panel $A$ uses OLS regressions and control for neighborhood fixed effects. Panel $B$ uses quantile regressions (median). Significance levels: $* 10 \%, * * 5 \%, * * 1 \%$ (s.e. clustered by moving week).

levels to absorb part of the household heterogeneity. The effect is smaller in $2002(0.87 \%$ for the mean and for the median), a finding that is consistent with the rebound in electricity use levels in 2002, but it remains positive and significant. In the last column, we estimate the long-run effect in a specification that pools the years between 2003 and 2005 (adding year fixed effects). The long-run effect amounts to an increase in electricity use of $0.49 \%$ for the mean and $0.86 \%$ for the median for each $10 \%$ increase in the quota of same-week movers. ${ }^{16}$

In sum, the degree of hysteresis - the ratio of the long-run effect to the short-run effect implied by the estimates in this analysis $\left(\frac{.049}{.138}=.355\right.$ and $\left.\frac{.086}{.153}=.562\right)$ is comparable to the degree of hysteresis implied by the estimates based on the utility-level data $\left(\frac{-.123}{-.264}=.466\right.$ in Table 2$)$.

\section{Mechanisms of hysteresis}

We end the empirical analysis by providing some qualitative evidence for the mechanisms of hysteresis behind our results using the household-level data from the PPH surveys. ${ }^{17}$

\footnotetext{
${ }^{16}$ We show in Appendix C that point estimates are relatively stable across years between 2003 and 2005.

${ }^{17}$ We present additional results and attempts at shedding light on the mechanisms of hysteresis in Appendix D.
} 
A. Main sources of electricity use prior to the crisis. - Table 4A documents the main sources of household electricity use in the Southeast/Midwest prior to the crisis. It displays the average quantity per household for major electrical appliances (in terms of average electricity use) from the 1998-1999 PPH surveys conducted in a representative sample of 6,482 customers of eight distribution utilities. It also displays the average electricity use for each appliance (see Appendix D for details on this computation). The main sources of electricity use differ substantially from those in the U.S. Electric showers, which are popular technologies for water heating in several developing countries (they have a low fixed cost), consume the most electricity. Next come refrigerators, lights, TVs, and freezers. Air conditioners only account for a small share of electricity use.

B. Mechanisms behind the estimated long-run effect.- Table 4B documents the main mechanisms of hysteresis in our setting, as reported by the 4,579 customers of the same distribution utilities surveyed in the 2004-2005 PPH surveys. Households were asked how their usage of each major domestic appliance at the time compared with their pre-crisis usage (for those that owned the appliance prior to the crisis). For every appliance, a large share of households reported that they used it less than before the crisis (e.g., 39\% for electric showers, which temperature can be adjusted; $41 \%$ for lights; $21 \%$ for freezers). One notable exception is for refrigerators, but we would not expect much flexibility in their utilization. A sizable share of households reported disconnecting or disposing of their freezer (17\%; households can rely on the smaller freezer unit in their refrigerator). Very few households reported replacing appliances with more energy-efficient models, except for lights (8\%). In subsequent survey questions, households reported continuing to use more energy-efficient (e.g., fluorescent) lightbulbs after the crisis (see Appendix D).

Thus, the main reported mechanism of hysteresis is a change in the way households use their electrical appliances. The apparent lack of sizable investments in physical capital is consistent with the fact that appliance manufacturers expected ex-ante, and reported ex-post, losses from the crisis (Folha de São Paulo, June 5, 2001 and March 6, 2002). In 2001, Brazil was also the country with the highest real interest rate in the World Development Indicators (44.65\%), limiting households' ability to finance physical investments. The evidence in Table 4B remains suggestive, however. 
Table 4: Qualitative evidence for the mechanisms of hysteresis

\begin{tabular}{lcccccc}
\hline & $\begin{array}{l}\text { Electric } \\
\text { shower } \\
(1)\end{array}$ & Refrigerator & Freezer & Lights & TV & AC \\
& $(2)$ & $(3)$ & $(4)$ & $(5)$ & $(6)$ \\
\hline $\begin{array}{l}\text { A. Main sources of electricity use prior to the crisis } \\
\text { Average quantity before the crisis }\end{array}$ & .97 & .99 & .20 & 8.45 & 1.39 & .10 \\
Average kWh/month before the crisis & 58.14 & 41.71 & 7.88 & 42.54 & 15.63 & 2.78 \\
B. Reported mechanisms of persistent changes in electricity use (2004/2005 survey) & & \\
Share of respondents who report that they: & & & & & & \\
(1) Use appliance as much as before the crisis & .60 & .90 & .61 & .51 & n.a. & .32 \\
(2) Use appliance less than before the crisis & .39 & .07 & .21 & .41 & n.a. & .60 \\
(3) Disconnected or disposed of the appliance & .01 & 0 & .17 & 0 & n.a. & .05 \\
(4) Substituted a more energy-efficient model & 0 & .03 & .01 & .08 & n.a. & .03 \\
Number of respondents & 4,225 & 4,432 & 784 & 4,500 & & 257 \\
\hline
\end{tabular}

Notes: The table uses the microdata from the PPH surveys for eight distribution utilities in the Southeast/Midwest. Panel A displays the average number per household and the inputted average monthly electricity use in the 1998/1999 survey for the appliances listed above each column. Panel B tabulates the share of households in the 2004/2005 survey that chose each of the statements listed on the left-hand side as their answer to a question about their usage after the crisis of the appliance in each column (only for households that owned that appliance prior to the crisis).

\section{Hysteresis and the welfare evaluation of corrective policies}

We now examine how the possibility that a policy may alter households' choices persistently - even if it is no longer in place (as the empirical evidence shows) - affects the way we typically evaluate the welfare effect of corrective policies in the literature. In so doing, we highlight how estimates of the persistent effect of a short-run policy can be used to inform the welfare effect of both short-run and long-run policies. We end by using our own estimate to illustrate the implications of hysteresis for the welfare evaluation of such policies quantitatively. Electricity use is our running example, but we emphasize that the theoretical results in this section are not specific to the context of our application because they are based on a very standard consumer model. Finally, we focus on the intuition for our results below, but we provide more details and all derivations in Appendix E.

\subsection{Benchmark framework}

We begin with a benchmark framework in order to focus on the key implications of hysteresis for the welfare evaluation of corrective policies. We relax some of its assumptions later. 
A. Consumer problem. - We consider the problem of a representative household deciding how much electricity to use in each of two periods. The household derives utility from the services created by electricity use $x_{t}$ with unit price $p_{t}$ and from a numeraire $c_{t}$, given its income $y_{t}$ in periods $t=\{1,2\}$. The per-period utility from electricity services is $v\left(x_{t}, s_{t}\right)$ and it is strictly increasing and concave in $x_{t}$. This function captures the mapping from electricity use to utility, and implicitly involves usage and electrical appliance choices. The variable $s_{t}$ is the household's propensity to consume electricity and it captures the energy inefficiency of the mapping from electricity use to utility. We assume that $\frac{\partial v\left(x_{t}, s_{t}\right)}{\partial s_{t}} \leq 0$ : a household with a higher propensity to consume derives less utility from a given level of electricity use. This assumption essentially defines $s_{t}$. We also assume that $\frac{\partial^{2} v\left(x_{t}, s_{t}\right)}{\partial x_{t} \partial s_{t}}>0$ : the higher the propensity to consume, the higher the marginal benefit from electricity use. This complementarity assumption ensures that a household with a higher propensity to consume uses more electricity. Finally, the household can make investments, $I_{t}$, to reduce its propensity to consume, $\frac{\partial s_{t}}{\partial I_{t}} \leq 0$, at strictly increasing and convex costs $\kappa_{t}\left(I_{t}\right)$.

One can interpret $s_{t}$ as capturing the energy inefficiency of the household's appliances, and $\kappa_{t}\left(I_{t}\right)$ as capturing the costs of adopting more energy-efficient technologies. However, our setup is general such that $s_{t}$ and $\kappa_{t}\left(I_{t}\right)$ can also capture, e.g., the household's lack of knowledge about how to use electricity efficiently and the costs of learning more energy-efficient behaviors, respectively.

We allow for hysteresis by letting choices in period 1 affect the propensity to consume in period 2, which in turn affects electricity use through the complementarity assumption. First, we allow investments in period 1 to affect the propensity to consume in period 2 by assuming $\frac{\partial s_{t}}{\partial s_{t-1}} \geq 0$. Investments in adopting new technologies or learning more energy-efficient behaviors may affect the household's propensity to use electricity persistently because investments costs may not be easily reverted and the assets created may not depreciate rapidly (e.g., Brandon et al., 2017). Second, we allow consumption choices in period 1 to affect the propensity to consume in period 2 directly by assuming $\frac{\partial s_{t}}{\partial x_{t-1}} \geq 0$. Like in experience-good models, the household may learn more energy-efficient behaviors by simply experimenting with different levels of electricity use in period 1 (e.g., Larcom, Rauch and Willems, 2017). This also accommodates habit formation 
models, in which the marginal utility of consumption depends on past consumption levels (Becker and Murphy, 1988). This setup thus encompasses a wide range of mechanisms of hysteresis.

The household then make choices by solving the following problem:

$$
\begin{gathered}
\max _{x_{1}, x_{2}, I_{1}, I_{2}} V=U_{1}+\beta U_{2}=y_{1}-p_{1} x_{1}-\kappa_{1}\left(I_{1}\right)+v\left(x_{1}, s_{1}\right)+\beta\left[y_{2}-p_{2} x_{2}-\kappa_{2}\left(I_{2}\right)+v\left(x_{2}, s_{2}\right)\right] \\
\text { s.t. } s_{t}=s_{t}\left(s_{t-1}, x_{t-1}, I_{t}\right) \text { for } t=1,2 \text { and }\left(s_{0}, x_{0}\right) \text { given, }
\end{gathered}
$$

where $V$ is its lifetime utility and $\beta$ accounts for discounting and possible differences in the relative length of the two periods. The quasi-linearity assumption is standard in the literature (e.g., Allcott and Taubinsky, 2015) and it allows us to abstract from redistributive concerns and income effects.

The first-order conditions for this problem are:

$$
\begin{aligned}
& \frac{\partial v\left(x_{1}, s_{1}\right)}{\partial x_{1}}+\beta \frac{\partial v\left(x_{2}, s_{2}\right)}{\partial s_{2}} \frac{\partial s_{2}}{\partial x_{1}}=p_{1} ; \quad\left[\frac{\partial v\left(x_{1}, s_{1}\right)}{\partial s_{1}}+\beta \frac{\partial v\left(x_{2}, s_{2}\right)}{\partial s_{2}} \frac{\partial s_{2}}{\partial s_{1}}\right] \frac{\partial s_{1}}{\partial I_{1}}-\kappa_{1}^{\prime}\left(I_{1}\right)=0 \\
& \frac{\partial v\left(x_{2}, s_{2}\right)}{\partial x_{2}}=p_{2} \quad ; \quad \frac{\partial v\left(x_{2}, s_{2}\right)}{\partial s_{2}} \frac{\partial s_{2}}{\partial I_{2}}-\kappa_{2}^{\prime}\left(I_{2}\right)=0
\end{aligned}
$$

They imply that the household uses more electricity if its propensity to consume is higher $\left(\frac{\partial^{2} v_{t}}{\partial x_{t} \partial s_{t}}>\right.$ 0 ); that it uses less electricity in period 1 if its future propensity to consume depends on past choices $\left(\frac{\partial s_{2}}{\partial x_{1}}>0\right)$; and that it invests more in period 1 if investments are persistent $\left(\frac{\partial s_{1}}{\partial I_{1}}<0, \frac{\partial s_{2}}{\partial s_{1}}>0\right)$.

B. Market equilibrium. - We begin by assuming that electricity is priced at a constant marginal cost such that we can illustrate the role of hysteresis using simple consumer surplus concepts. The first-order conditions to the household's problem in equation (5) and baseline electricity prices ( $p_{10}$ and $\left.p_{20}\right)$ then determine baseline electricity use and investment levels $\left(x_{10}, x_{20}, I_{10}\right.$, and $\left.I_{20}\right)$.

C. Corrective policies. - We motivate the need for corrective policies by assuming that social welfare, $W$, may differ from private welfare, $V$, because of externalities from electricity use, $d_{t} x_{t}$. Without loss of generality, we assume negative externalities such that $d_{t}$ captures the marginal damage from electricity use in period $t$ and welfare can be written $W=V-d_{1} x_{1}-\beta d_{2} x_{2}$. We consider both a short-run policy - aimed at reducing electricity use to $\overline{x_{1}}<x_{10}$ in period 1 only - and a long-run policy - aimed at reducing electricity use to $\overline{x_{1}}<x_{10}$ in period 1 and 
to $\overline{x_{2}}<x_{20}$ in period $2 .{ }^{18}$ We assume that these policies are implemented through traditional instruments, i.e., quotas, taxes, or subsidies. The welfare effect of the short-run policy is then $\Delta W^{S R}=W\left(\overline{x_{1}}, x_{2}\left(\overline{x_{1}}\right), I_{1}\left(\overline{x_{1}}\right), I_{2}\left(\overline{x_{1}}\right)\right)-W\left(x_{10}, x_{20}, I_{10}, I_{20}\right)$, where $x_{2}\left(\overline{x_{1}}\right), I_{1}\left(\overline{x_{1}}\right)$, and $I_{2}\left(\overline{x_{1}}\right)$ denote privately optimal levels of these variables given the short-run policy. The welfare effect of the long-run policy is $\Delta W^{L R}=W\left(\overline{x_{1}}, \overline{x_{2}}, I_{1}\left(\overline{x_{1}}, \overline{x_{2}}\right), I_{2}\left(\overline{x_{1}}, \overline{x_{2}}\right)\right)-W\left(x_{10}, x_{20}, I_{10}, I_{20}\right)$, where $I_{1}\left(\overline{x_{1}}, \overline{x_{2}}\right)$ and $I_{2}\left(\overline{x_{1}}, \overline{x_{2}}\right)$ denote privately optimal levels of these variables given the long-run policy.

D. Evaluating welfare effects when assuming away hysteresis.-A researcher who assumes away hysteresis implicitly assumes $s_{t}\left(s_{0}, I_{t}\right)$ for a given $s_{0}$, i.e., that the household's propensity to consume does not depend on past consumption choices, and that investments fully depreciate between periods. In that case, she can evaluate the welfare effect of both policies using:

$$
\begin{aligned}
\Delta W_{N o H}^{S R} & =\int_{x_{10}}^{\overline{x_{1}}}\left[p_{1}\left(x_{1}\right)-p_{10}\right] d x_{1}-d_{1}\left[\overline{x_{1}}-x_{10}\right] \\
\Delta W_{N o H}^{L R} & =\int_{x_{10}}^{\overline{x_{1}}}\left[p_{1}\left(x_{1}\right)-p_{10}\right] d x_{1}+\beta \int_{x_{20}}^{\overline{x_{2}}}\left[p_{2}\left(x_{2}\right)-p_{20}\right] d x_{2}-d_{1}\left[\overline{x_{1}}-x_{10}\right]-\beta d_{2}\left[\overline{x_{2}}-x_{10}\right]
\end{aligned}
$$

Equations (6) and (7) are one-period and two-period versions of the textbook formula for the welfare effect of a corrective policy. The welfare gain comes from the correction of the externalities. It depends on the marginal damage $d_{t}$ and on the change in electricity use in each period $\left(\overline{x_{t}}-x_{t 0} \leq 0\right)$. The welfare loss comes from the reduction in private welfare (i.e., consumer surplus) from inducing households to deviate from privately optimal electricity use choices. As illustrated in Figure 6, the welfare loss is captured by Harberger "triangles" in each period, i.e., the area under the (inverse) demand curve $p_{t}\left(x_{t}\right)$ and above the baseline price $p_{t 0}$ between the consumption levels with and without the policy. ${ }^{19}$ The slope of the demand curve captures the change in private welfare because it accounts for changes in the household's utility due to changes in $x_{t}$ and to endogenous changes in other choice variables (e.g., $I_{t}$ ) following changes in $x_{t}$. As a result, it does not matter how the household reduces electricity use: it optimally chooses among its margins of adjustments

\footnotetext{
${ }^{18}$ Note that this setup allows the government to have short-run or long-run goals for these policies: it has a short-run (resp. long-run) goal if the marginal damage $d_{t}$ is assumed to be nil in period 2 (resp. to be positive in both periods).

${ }^{19}$ The corrective tax implementing these policies is $\overline{\tau_{t}}=p_{t}\left(\overline{x_{t}}\right)-p_{t 0}$ and the optimal tax is simply $\tau_{t}^{*}=d_{t}$.
} 
Figure 6: The loss in private welfare from corrective policies in the benchmark framework

(a) Period 1

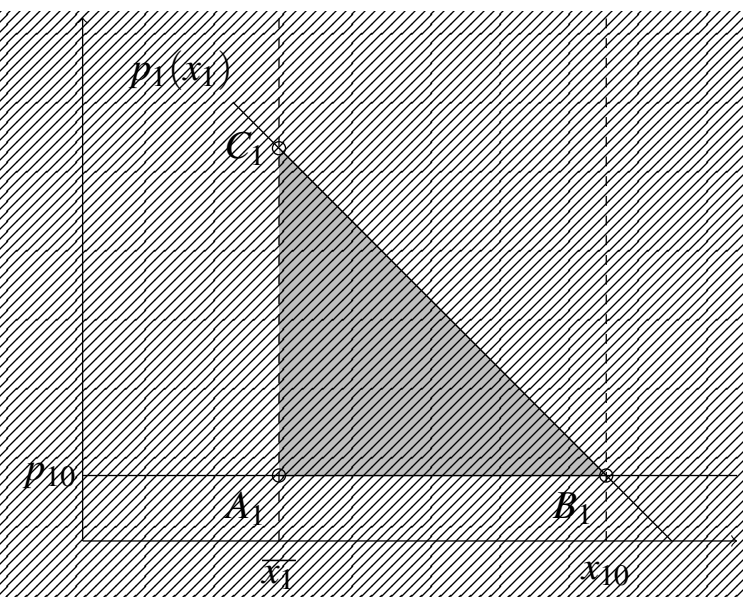

(b) Period 2

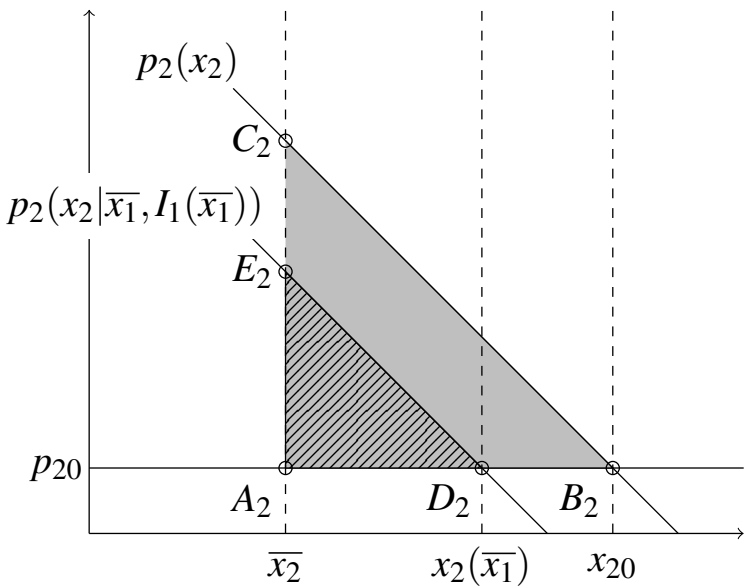

Notes: The figure illustrates the loss in private welfare from corrective policies in the benchmark framework for the case of linear demand curves. The triangles $A_{1} B_{1} C_{1}, A_{2} B_{2} C_{2}$, and $A_{2} D_{2} E_{2}$ correspond to the first integral in equations (6)-(9), the second integral in equation (7), and the second integral in equation (9), respectively.

and the associated changes in its utility are reflected in the demand curve. ${ }^{20}$

E. Evaluating welfare effects when allowing for hysteresis. - A researcher who allows for hysteresis recognizes that the household's propensity to consume may depend on past choices, $s_{t}\left(s_{t-1}, x_{t-1}, I_{t}\right)$. In that case, the formula for the welfare effect of the short-run policy becomes:

$$
\Delta W^{S R}=\int_{x_{10}}^{\overline{x_{1}}}\left[p_{1}\left(x_{1}\right)-p_{10}\right] d x_{1}-d_{1}\left[\overline{x_{1}}-x_{10}\right]-\beta d_{2}\left[x_{2}\left(\overline{x_{1}}\right)-x_{20}\right] .
$$

The period-2 demand curve, $p_{2}\left(x_{2} \mid \overline{x_{1}}, I_{1}\left(\overline{x_{1}}\right)\right)$, may shift inward following a short-run policy if the household's propensity to consume in period 2 depends on its choices in period 1, as illustrated in Figure 6b. As a result, the household consumes $x_{2}\left(\overline{x_{1}}\right) \leq x_{20}$ at price $p_{20}$. However, the slope of the period-1 demand curve continues to capture the change in private welfare due to the shortrun policy, including from endogenous changes in $x_{2}$ and $I_{2}$. The only novelty in equation (8) is that one must now account for a potential correction of externalities in period 2 because of the hysteresis in electricity use. By assuming away hysteresis, one would therefore underestimate the

\footnotetext{
${ }^{20}$ This standard result assumes no pre-existing distortions on the household's margins of adjustments (Chetty, 2009).
} 
welfare gain of the short-run policy in this benchmark framework. ${ }^{21}$

The persistent effect of the short-run policy, $x_{2}\left(\overline{x_{1}}\right)-x_{20}$, is the new empirical object to estimate for evaluating its welfare effect. More precisely, it is the persistent effect of a policy that was expected to be short-run, as in our application. This qualifier is important because studies that estimate the persistent effect of a policy rarely specify whether it was expected to last longer than it did. Expectations matter because the household may make investments in period 1 if it expects the policy to continue, which it would not make if it knew that the policy were to be temporary. ${ }^{22}$

In the case of the long-run policy, the formula for the welfare effect can be written:

$$
\begin{aligned}
\Delta W^{L R}= & \int_{x_{10}}^{\overline{x_{1}}}\left[p_{1}\left(x_{1}\right)-p_{10}\right] d x_{1}+\beta \int_{x_{2}\left(\overline{x_{1}}\right)}^{\overline{x_{2}}}\left[p_{2}\left(x_{2} \mid \overline{x_{1}}, I_{1}\left(\overline{x_{1}}\right)\right)-p_{20}\right] d x_{2}-d_{1}\left[\overline{x_{1}}-x_{10}\right]-\beta d_{2}\left[\overline{x_{2}}-x_{20}\right] \\
& +\left[W\left(\overline{x_{1}}, \overline{x_{2}}, I_{1}\left(\overline{x_{1}}, \overline{x_{2}}\right), I_{2}\left(\overline{x_{1}}, \overline{x_{2}}\right)\right)-W\left(\overline{x_{1}}, \overline{x_{2}}, I_{1}\left(\overline{x_{1}}\right), I_{2}\left(\overline{x_{1}}, \overline{x_{2}}, I_{1}\left(\overline{x_{1}}\right)\right)\right)\right]
\end{aligned}
$$

The welfare gain from correcting the externalities is identical to that in equation (7). The difference comes from the loss in private welfare, which we divide into three parts in equation (9). As in equation (8), the first integral captures the loss from the period-1 policy, due to the change in $x_{1}$ to $\overline{x_{1}}$ and in the other choice variables to $x_{2}\left(\overline{x_{1}}\right), I_{1}\left(\overline{x_{1}}\right)$, and $I_{2}\left(\overline{x_{1}}\right)$. The second integral captures the loss from the period-2 policy, if the household had not anticipated the period-2 policy while in period 1. This term accounts for changes in private welfare due to the additional change in $x_{2}$ to $\overline{x_{2}}$ and in $I_{2}$ to $I_{2}\left(\overline{x_{1}}, \overline{x_{2}}, I_{1}\left(\overline{x_{1}}\right)\right)$. Finally, the household could have anticipated the period-2 policy and chosen another level of investment in period $1, I_{1}\left(\overline{x_{1}}, \overline{x_{2}}\right)$, and consequently another level of investment in period $2, I_{2}\left(\overline{x_{1}}, \overline{x_{2}}\right)$. The impact on private welfare is captured by the last term in equation (9). By revealed preferences, this term increases private welfare, as the only reason to make different investments in period 1 would be to mitigate the overall loss in private welfare. ${ }^{23}$

\footnotetext{
${ }^{21}$ The optimal corrective tax for a short-run policy becomes: $\tau_{1}^{*}=d_{1}+\beta d_{2} \frac{d x_{2} / d \tau_{1}}{d x_{1} / d \tau_{1}}$. However, by Sandmo's targeting principle, the optimal policy will be a long-run policy if there are externalities in both periods. We note that Ito, Ida and Tanaka (2018), who document persistent effects for 3 months after a policy ended, use a formula similar to the one derived here to evaluate the welfare implications of that short-run policy (see their Web Appendix).

${ }^{22}$ These extra investments, which may contribute to the persistent effect of the policy, are ex-post suboptimal and imply losses in private welfare that are not accounted for by the demand curve in period 1 .

${ }^{23}$ The optimal corrective taxes for a long-run policy remain unchanged $\tau_{t}^{*}=d_{t}$.
} 
Comparing equations (7) and (9) highlights three sources of bias from assuming away hysteresis when evaluating the loss in private welfare. First, part of the change in electricity use in period 2 , from $x_{20}$ to $x_{2}\left(\overline{x_{1}}\right)$, is due to the period-1 policy. The associated change in private welfare should not be double-counted, which is why the second integral in equation (9) is only taken from $x_{2}\left(\overline{x_{1}}\right)$ to $\overline{x_{2}}$. This is illustrated in Figure $6 \mathrm{~b}$. The persistent effect of the short-run policy (again, provided that it was expected to be short run) is the new empirical object to estimate for evaluating this first source of bias, which corresponds to the trapezoid $D_{2} B_{2} C_{2} E_{2}$ in Figure $6 \mathrm{~b}$.

Second, the change in the period-2 propensity to consume due to the period-1 policy may have changed not only the location but also the slope of the period- 2 demand curve. Whether this leads to a bias depends on the variation used to estimate that slope. A researcher who allows for hysteresis would estimate the slope of $p_{2}\left(x_{2} \mid \overline{x_{1}}, I_{1}\left(\overline{x_{1}}\right)\right)$ using price variation in period 2 following a short-run policy. There would be no bias if a researcher who assumes away hysteresis estimates the slope of $p_{2}\left(x_{2}\right)$ using the same variation. However, she may wrongly believe that the slopes of the demand curves in periods 1 and 2 are identical and use an estimate of the slope of $p_{1}\left(x_{1}\right)$ for $p_{2}\left(x_{2}\right)$ as well. In that case, she would overestimate (resp. underestimate) the loss in private welfare if the demand curve became more elastic (resp. inelastic) following the short-run policy.

Third, a researcher who assumes away hysteresis would fail to recognize that the household could make different investment choices in period 1 to mitigate its overall loss in private welfare. The last term in equation (9) is challenging to estimate. ${ }^{24}$ However, given that it is positive, we can abstract from it and still evaluate lower bounds for the welfare effect and for the overall bias from assuming away hysteresis. Note also that this source of bias only arises when costly investments can affect the household's future propensity to consume directly as captured by $\frac{\partial s_{t+1}}{\partial s_{t}} \frac{\partial s_{t}}{\partial I_{t}} \leq 0$.

F. Implementation. - An advantage of using welfare formulas such as the ones in equations (6)-(9) is that one can evaluate welfare effects by estimating or calibrating a few empirical objects rather than a fully-specified model. In practice, there are various approaches in the literature to

\footnotetext{
${ }^{24}$ First, one would need to measure the difference in period-1 investments, for all possible types of investments, in the case of a long-run policy and in the case of a short-run policy. Second, one would need to evaluate the change in private welfare resulting from such changes in investments, given electricity use levels $\overline{x_{1}}$ and $\overline{x_{2}}$.
} 
estimate marginal damages, and, for non-marginal changes, Harberger triangle formulas are "typically implemented under a linear or log-linear approximation to demand because data limitations preclude the estimation of higher-order properties of demand curves" (Chetty, 2009).

\subsection{Extensions}

Another advantage is that multiple combinations of model primitives are consistent with the same formulas, as long as demand curves capture agents' willingness to pay for the behavior at stake (Chetty, 2009), here electricity. For instance, we obtain similar formulas if we add heterogeneity, uncertainty (e.g., Sallee, 2014), or discrete investments (e.g., Dubin and McFadden, 1984) in the benchmark framework. Therefore, for this class of models, comparing equations (6)-(9) allows us to make qualitative statements regarding the bias from failing to take hysteresis into account when it is empirically relevant. This is summarized in the first row of each panel in Table 5. One would underestimate the welfare effect of a short-run policy by failing to account for a possible correction of externalities after the policy ended. One would underestimate the welfare effect of a long-run policy by overestimating the loss in consumer surplus in the long run (i.e., period 2). ${ }^{25}$

However, the welfare formulas and the implications of hysteresis may differ if we relax three key assumptions of the benchmark framework, which may be relevant in some applications, ours included (these extensions and the ones mentioned above are presented in details in Appendix E).

A. Social incentives. - The benchmark framework considers policies implemented through quotas, taxes, or subsidies. Yet, corrective policies sometimes include social incentives (e.g., peer pressure). In that case, the welfare formulas include another term because these incentives may give the household social (dis-)utility from its electricity use. This term is challenging to estimate (e.g., Allcott and Kessler, 2019), but it is identical whether or not hysteresis is assumed away. Thus, the implications of taking hysteresis into account are the same as in the benchmark framework. ${ }^{26}$

\footnotetext{
${ }^{25}$ This holds if researchers assuming away hysteresis do not use a much more elastic demand curve when evaluating equation (7). We assume that they use the same elasticity in Table 5, i.e., that the second source of bias is nil.

${ }^{26} \mathrm{It}$ is conceivable that a policy including social incentives may change social norms persistently, creating incentives for households to behave in a certain way even if the policy is no longer in place. In that case, the welfare implications of persistent changes in behaviors would be very different (see Appendix E). The evidence in Section 3.2 indicates
} 
B. Producer surplus. - The benchmark framework assumes that electricity is priced at a constant marginal cost. Yet, firms often have upward-sloping marginal cost curves or charge a mark-up over marginal cost. In those cases, the textbook formulas add a loss in producer surplus in period 1 for the short-run policy and in both periods for the long-run policy. With hysteresis, the formula for the short-run policy also includes a loss in producer surplus in period 2 from the unrealized surplus on the quantity that the firm does not sell because of the long-run effect of the policy. This term depends on the gap between price and marginal cost over the persistent reduction in electricity use. It is also negative, so the sign of the bias from assuming away hysteresis becomes ambiguous. For the long-run policy, the bias is unchanged because the loss in producer surplus is the same whether hysteresis is assumed away or not. This is summarized in the second row of each panel in Table 5.

C. Myopic beliefs. - The benchmark framework assumes away any behavioral considerations. Yet, households sometimes make optimization mistakes. For instance, in our context, the household may be myopic about its own hysteresis: it may maximize its "perceived" lifetime utility in period 1 , neglecting any effect of its choices on its future propensity to consume, but make decisions in period 2 based on its actual propensity to consume. Such a myopic household uses more electricity and invests less in reducing its propensity to consume in period 1 ; it also fails to predict its choices in period 2. A key normative question in this case is how to evaluate private welfare, given that demand curves may not capture the household's "true" willingness to pay for electricity.

A typical approach is to use the household's experienced utility. The Harberger triangle formulas in equations (6)-(9) then capture the losses in private welfare as perceived by the household. With hysteresis, these overestimate the true losses in private welfare and the welfare formulas include the correction of an "internality." The household overestimates its loss from reducing electricity use in period 1 , holding fixed its plans regarding period-2 choices (given $\frac{\partial v}{\partial s_{2}} \leq 0$ ). Moreover, it does not anticipate its gain from adjusting its plans once in period 2 (given $\frac{\partial^{2} v}{\partial x_{2} \partial s_{2}}>0$ ). The first component is challenging to estimate (e.g., Allcott and Taubinsky, 2015). The second component can be captured by a Harberger triangle that depends on the slope of the period-2 demand curve that the hysteresis is unlikely due to a persistent change in social norms in our application: households that moved at different times were comparable at baseline and were exposed to the same conservation appeals during the crisis. 
Table 5: The qualitative implications of taking hysteresis into account for welfare evaluation

\begin{tabular}{|c|c|c|c|c|c|}
\hline & $\begin{array}{l}\Delta \text { Consumer } \\
\text { Surplus } \\
t=2 \\
\quad(1)\end{array}$ & $\begin{array}{l}\Delta \text { Externality } \\
\qquad \begin{array}{l}t=2 \\
(2)\end{array}\end{array}$ & $\begin{array}{l}\Delta \text { Producer } \\
\text { Surplus } \\
t=2 \\
(3)\end{array}$ & $\begin{array}{l}\Delta \text { Internality } \\
\qquad \begin{array}{c}t=1,2 \\
(4)\end{array}\end{array}$ & $\begin{array}{c}\Delta \text { Welfare } \\
t=1,2 \\
\quad(5)\end{array}$ \\
\hline $\begin{array}{l}\text { Panel A. Short-run policy } \\
\text { Benchmark framework (and other extensions) } \\
\text { + Producer surplus } \\
\text { or Myopic beliefs (expected utility criteria) } \\
\text { or Myopic beliefs (ex-ante utility criteria) }\end{array}$ & $\begin{array}{l}=0 \\
=0 \\
=0 \\
=0\end{array}$ & $\begin{array}{l}\geq 0 \\
\geq 0 \\
\geq 0 \\
\geq 0\end{array}$ & $\leq 0$ & $\begin{array}{l}\geq 0 \\
\leq 0\end{array}$ & $\begin{array}{l}\geq 0 \\
\geq 0 \text { or } \leq 0 \\
\geq 0 \\
\geq 0 \text { or } \leq 0\end{array}$ \\
\hline $\begin{array}{l}\text { Panel B. Long-run policy } \\
\text { Benchmark framework (and other extensions) } \\
\text { + Producer surplus } \\
\text { or Myopic beliefs (expected utility criteria) } \\
\text { or Myopic beliefs (ex-ante utility criteria) }\end{array}$ & $\begin{array}{l}\geq 0 \\
\geq 0 \\
\geq 0 \\
=0\end{array}$ & $\begin{array}{l}=0 \\
=0 \\
=0 \\
=0\end{array}$ & $=0$ & $\begin{array}{l}\geq 0 \\
=0\end{array}$ & $\begin{array}{l}\geq 0 \\
\geq 0 \\
\geq 0 \\
=0\end{array}$ \\
\hline
\end{tabular}

Notes: The table highlights the implications of taking hysteresis into account for the welfare evaluation of corrective policies. Columns (1)-(4) correspond to different components of the welfare effect of short-run (panel A) and long-run (panel B) policies, and column (5) to their overall welfare effect. In each panel, the rows correspond to different frameworks discussed in Section 5. Each entry reports the sign of any bias from assuming away hysteresis based on the theory: " $\geq 0$ " vs. " $\leq 0$ " implies that taking hysteresis into account would increase vs. decrease welfare through the value of the corresponding component (" $=0$ " implies no effect, i.e., no bias). An empty cell implies that the component in that column is not relevant for welfare effects under the framework in that row.

and on the persistent effect of the short-run policy. As summarized in the third row of each panel in Table 5, the downward bias from assuming away hysteresis increases in this case.

Another approach is to use the household's ex-ante utility, disregarding any change in its willingness-to-pay for electricity from period 1 to period 2 . With hysteresis, the welfare formula for the short-run policy includes a loss in consumer surplus in that case because of an internality in period 2, as the persistent reduction in electricity use is privately suboptimal. This term can be captured by a Harberger triangle that depends on the slope of the period-1 demand curve and on the persistent effect of the short-run policy. It is also negative, so the sign of the bias from assuming away hysteresis becomes ambiguous. For the long-run policy, the three sources of bias in the benchmark framework disappear. This is summarized in the fourth row of each panel in Table 5.

\subsection{Illustrating the implications of hysteresis quantitatively}

We now use our estimate of the persistent effect of a short-run policy to illustrate the magnitude of the biases from assuming away hysteresis for the welfare evaluation of corrective policies, high- 
Table 6: Illustrating the implications of hysteresis for welfare evaluation quantitatively

\begin{tabular}{|c|c|c|c|c|c|c|c|c|}
\hline & \multicolumn{2}{|c|}{$\begin{array}{c}\Delta \text { Cons. Surplus } \\
\quad t=2\end{array}$} & \multicolumn{2}{|c|}{$\begin{array}{c}\Delta \text { Externality } \\
t=2\end{array}$} & \multicolumn{2}{|c|}{$\begin{array}{c}\Delta \text { Prod. Surplus } \\
t=2\end{array}$} & \multicolumn{2}{|c|}{$\begin{array}{c}\Delta \text { Internality } \\
t=1,2\end{array}$} \\
\hline & $\begin{array}{l}\text { Hyst. } \\
\text { (1a) }\end{array}$ & $\begin{array}{l}\text { No Hyst. } \\
\text { (1b) }\end{array}$ & $\begin{array}{l}\text { Hyst. } \\
(2 \mathrm{a})\end{array}$ & $\begin{array}{l}\text { No Hyst. } \\
\text { (2b) }\end{array}$ & $\begin{array}{l}\text { Hyst. } \\
\text { (3a) }\end{array}$ & $\begin{array}{l}\text { No Hyst. } \\
\text { (3b) }\end{array}$ & $\begin{array}{l}\text { Hyst. } \\
\text { (4a) }\end{array}$ & $\begin{array}{l}\text { No Hyst. } \\
\text { (4b) }\end{array}$ \\
\hline Panel A. Short-run policy & & & & & & & & \\
\hline Benchmark framework & 0 & 0 & 1.6 & 0 & & & & \\
\hline + Producer surplus & 0 & 0 & 1.6 & 0 & -8.0 & 0 & & \\
\hline or Myopic beliefs (expected utility) & 0 & 0 & 1.6 & 0 & & & $\geq 2.6$ & 0 \\
\hline or Myopic beliefs (ex-ante utility) & 0 & 0 & 1.6 & 0 & & & -2.6 & 0 \\
\hline Panel B. Long-run policy & & & & & & & & \\
\hline Benchmark framework & $\geq-2.5$ & -9.7 & 3.1 & 3.1 & & & & \\
\hline + Producer surplus & $\geq-2.5$ & -9.7 & 3.1 & 3.1 & -15.2 & -15.2 & & \\
\hline or Myopic beliefs (expected utility) & $\geq-2.5$ & -9.7 & 3.1 & 3.1 & & & $\geq 2.6$ & 0 \\
\hline or Myopic beliefs (ex-ante utility) & -9.7 & -9.7 & 3.1 & 3.1 & & & 0 & 0 \\
\hline
\end{tabular}

Notes: The table reports the magnitude of different components of the welfare effect of short-run (panel A) and longrun (panel B) policies (columns 1-4), taking hysteresis into account or not (columns a and b), based on the calculations in Section 5.3. All estimates are in percentage of the total electricity bills in the Southeast/Midwest from March 2002 to December 2014. In each panel, the rows correspond to the different frameworks discussed in Section 5. An empty cell implies that the component in that column is not relevant for welfare effects under the framework in that row.

lighted in the theory. Specifically, Table 6 reports estimates of the four welfare components in Table 5, taking hysteresis into account or assuming it away. We provide the details for our calculations in Appendix F, but we note here that they assume a linear demand curve with a slope consistent with our own estimate of the price elasticity of residential electricity use (-.31) in the Southeast/Midwest after the crisis. ${ }^{27}$ All estimates in Table 6 are in percentage of the total electricity bills in the Southeast/Midwest post-crisis, i.e., from March 2002 to December 2014.

A. Short-run policy.- We begin by illustrating the implications of taking hysteresis into account for the welfare effect of the short-run policy studied in the paper. The benchmark framework highlights that a bias may arise from ignoring a long-run correction of externalities. The policy was implemented because of an increase in the (shadow) marginal cost of electricity generation rather than to correct externalities. Yet, as in other countries, electricity generation in Brazil likely creates external costs. Using data on GHG emissions from electricity generation, our own estimate of marginal distribution losses, and a value of the social cost of carbon from the EPA, we evaluate "global" externalities at US\$.0136 per kWh consumed. Using reports on the electricity saved by

\footnotetext{
${ }^{27}$ For robustness, we present estimates assuming instead a log-linear demand curve in Appendix F. The elasticity is estimated using quasi-experimental variation in yearly tariffs across distribution utilities (see Appendix F).
} 
the energy-efficiency programs of the Brazilian government, and their costs, we evaluate the "local" value of electricity savings at US\$.0106 per kWh. Combining these estimates for $d_{2},{ }^{28}$ the long-run correction of externalities due to the $12 \%$-reduction in electricity use post-crisis increases the welfare effect of the energy-saving program by $1.6 \%$ of electricity bills in that period.

The hysteresis in electricity use also led to a long-run loss in producer surplus, however, because electricity was priced above marginal cost over that period. Using data on the marginal cost of electricity generation and our estimate of marginal distribution losses (Borenstein and Bushnell, 2018), we find that the price per kWh was more than twice the marginal cost of electricity distribution. This implies a long-run loss in producer surplus of $8 \%$ of electricity bills post-crisis, which far exceeds the welfare gain from the long-run correction of externalities. Thus, taking hysteresis into account would likely decrease the welfare effect of the temporary energy-saving program.

Finally, Table 6 reports that the additional source of welfare gain (using the expected utility criteria) or welfare loss (using the ex-ante utility criteria) with myopic households could be sizable ( $2.6 \%$ of electricity bills). ${ }^{29}$ We do not have evidence for or against myopia and we have no reason to take a stand on the relevant normative criteria. These estimates should be seen as highlighting the importance of considering optimization mistakes for evaluating the implications of hysteresis.

B. Long-run policy. - The energy-saving program was temporary, but to illustrate the implications of hysteresis for long-run policies, we consider a hypothetical policy aimed at changing electricity use by $\frac{\bar{x}_{1}-x_{10}}{x_{10}}=\frac{\bar{x}_{2}-x_{20}}{x_{20}}=-23 \%$ from June 2001 to December 2014. Period 1 in our framework is assumed to correspond to the first 9 months and period 2 to the following 154 months. We also assume that the period-1 policy would reduce electricity use by $12 \%$ in period 2 , even in absence of any policy in that period. Taking hysteresis into account, a researcher would evaluate the loss in consumer surplus for the period-2 policy at $2.5 \%$ of electricity bills post-crisis. By contrast, assuming away hysteresis, one would evaluate it at $9.7 \%$ of electricity bills post-crisis, thus

\footnotetext{
${ }^{28}$ Borenstein and Bushnell (2018) estimates a higher marginal damage for the U.S. (US\$.0621 vs. US\$.0242 here), but a much larger share of electricity generation comes from hydropower rather than fossil fuel in Brazil.

${ }^{29}$ The estimates are equal in absolute value between the two cases because we use the same slope for the period-1 and period- 2 demand curves. The estimate is only a lower bound with the experienced utility criteria (thus, the $\geq$ sign in Table 6) because we can only evaluate the second component of the additional source of welfare gain in that case.
} 
overestimating it by $285 \% .{ }^{30}$ Moreover, this figure only takes into account the hysteresis due to the first nine months of the policy and it abstracts from the third source of bias for long-run policies highlighted in the theory (thus, the $\geq$ sign in Table 6). Therefore, if long-run corrective policies may lead to large losses in consumer surplus when demand is relatively inelastic, as for electricity use, one may greatly overestimate such losses by failing to account for hysteresis. ${ }^{31}$

Finally, Table 6 shows that the bias could be even larger with myopic households if we use their experienced utility as normative criteria, but that there could be no bias at all if we use their ex-ante utility. This highlights again the importance of taking into account behavioral considerations.

\section{Conclusion}

This paper combined evidence and theory to highlight the importance of taking hysteresis into account for the welfare evaluation of corrective policies. We provided stark evidence of hysteresis by studying the persistent effect of a temporary energy-saving program. We then extended the traditional policy analysis of corrective policies and showed how estimates of the persistent effect of a short-run policy could be used to inform the welfare effect of both short-run and long-run policies in the presence of hysteresis. Importantly, our extension is not specific to our application, so it can be used to guide the welfare evaluation of corrective policies in other settings where a policy may alter households' choices persistently, even after it is not longer in place.

We would like to end by emphasizing the relevance of our application. There is a lot of interest in policies aimed at large long-run changes in energy use (e.g., IPCC, 2014). However, such policies are rarely implemented, partly because of the potentially severe losses in private surplus that they would create. At the same time, hysteresis may be more important in those cases, compared to nudges or shorter-lived policies. Learning effects are more likely when agents must depart fur-

\footnotetext{
${ }^{30}$ This figure is similar (288\%) if we assume a log-linear demand curve.

${ }^{31}$ In fact, Table 6 shows that, taking hysteresis into account, the welfare effect of the policy in period 2 becomes positive in the benchmark framework: the loss in consumer surplus becomes smaller than the welfare gain from the correction of externalities ( $3.1 \%$ of electricity bills). At the same time, Table 6 shows that the loss in producer surplus is likely much larger than the welfare gain from correcting externalities in our context ( $15.2 \%$ of electricity bills).
} 
ther from their usual levels of behavior; adopting new technologies may involve fixed costs; and hysteresis in a rational habit formation model relies on pushing agents far enough from their prior steady state (Becker and Murphy, 1988). Therefore, the policy that we study, which was only implemented because of a dramatic energy crisis, gives us a rather unique opportunity to shed light on the consequences of policies aimed at changes in energy use of this magnitude. In particular, it allows us to show that failing to take hysteresis into account may greatly overestimate the loss in consumer surplus for policies aimed at such large changes for the long run. An exciting question that arises from our findings is which policies would best induce persistent changes in households' choices, particularly at an earlier stage of development, to limit the growth in energy demand.

\section{References}

Acemoglu, D., P. Aghion, L. Bursztyn, and D. Hemous. 2012. "The Environment and Directed Technical Change.” A. E. R., 102(1): 131-166.

Acland, D., and M. R. Levy. 2015. "Naiveté, projection bias, and habit formation in gym attendance." Management Science, 61(1): 146-160.

Allcott, H., and D. Taubinsky. 2015. "Evaluating Behaviorally-Motivated Policy: Experimental Evidence from the Lightbulb Market.” A. E. R., 105(8): 2501-2538.

Allcott, H., and J. Kessler. 2019. "The Welfare Effects of Nudges: A Case Study of Energy Use Social Comparisons." American Econ. J.: Appl. Econ., 11(1): 236-276.

Allcott, H., and T. Rogers. 2014. "The Short-Run and Long-Run Effects of Behavioral Interventions: Experimental Evidence from Energy Conservation.” A. E. R., 104(10): 3003-3037.

Barreca, A., K. Clay, O. Deschenes, M. Greenstone, and J. S Shapiro. 2016. "Adapting to climate change: The remarkable decline in the US temperature-mortality relationship over the twentieth century." J. P. E., 124(1): 105-159.

Becker, G., and K. Murphy. 1988. “A Theory of Rational Addiction.” J. P. E., 96(4): 675-700. 
Borenstein, Severin, and James Bushnell. 2018. "Do Two Electricity Pricing Wrongs Make a Right? Cost Recovery, Externalities, and Efficiency.” NBER Working Paper, 24756.

Brandon, A., P. Ferraro, J. List, R. Metcalfe, M. Price, and F. Rundhammer. 2017. "Do The Effects of Social Nudges Persist? Theory and Evidence from 38 Natural Field Experiments." NBER Working Paper, 23277.

Bryan, G., S. Chowdhury, and A. M. Mobarak. 2014. "Underinvestment in a Profitable Technology: The Case of Seasonal Migration in Bangladesh.” Econometrica, 82(5): 1671-1748.

Charness, G., and U. Gneezy. 2009. "Incentives to Exercise.” Econometrica, 77(3): 909-931.

Chetty, R. 2009. "Sufficient Statistics for Welfare Analysis: A Bridge Between Structural and Reduced-Form Methods." Annual Rev. Econ., 1: 451-488.

Davis, L., A. Fuchs, and P. Gertler. 2014. "Cash for coolers: evaluating a large-scale appliance replacement program in Mexico.” American Econ. J.: Econ. Policy, 6(4): 207-238.

Dixit, A. 1989. "Entry and Exit Decisions under Uncertainty.” J. P. E., 97: 620-638.

Dubin, J., and D. McFadden. 1984. "An econometric analysis of residential electric appliance holdings and consumption." Econometrica, 52(2): 345-362.

Dupas, P. 2014. "Short-Run Subsidies and Long-Run Adoption of New Health Products: Evidence From a Field Experiment." Econometrica, 82(1): 197-228.

Ferraro, P. J., and M. K. Price. 2013. "Using nonpecuniary strategies to influence behavior: evidence from a large-scale field experiment." Rev. Econ. and Statis., 95(1): 64-73.

Fujiwara, T., K. Meng, and T. Vogl. 2016. "Estimating Habit Formation in Voting." American Econ. J.: Appl. Econ., 8(4): 160-188.

Giné, X., D. Karlan, and J. Zinman. 2010. "Put your money where your butt is: a commitment contract for smoking cessation.” American Econ. J.: Appl. Econ., 213-235.

Greenstone, M., and R. Hanna. 2014. "Environmental regulations, air and water pollution, and infant mortality in India.” A. E. R., 104(10): 3038-3072. 
Hintermann, B., and A. Lange. 2013. "Learning abatement costs: On the dynamics of the optimal regulation of experience goods." J. Env. Econ. and Management, 66(3): 625-638.

IPCC. 2014. "Climate Change 2014: IPCC Fifth Assessment Report."

Ito, K. 2015. “Asymmetric incentives in subsidies: Evidence from a large-scale electricity rebate program.” American Econ. J.: Econ. Policy, 7(3): 209-37.

Ito, K., T. Ida, and M. Tanaka. 2018. "Moral Suasion and Economic Incentives: Field Experimental Evidence from Energy Demand.” American Econ. J: Econ. Policy, 10(1): 240-267.

Kelman, J. 2001. "Desequilíbrio entre Oferta e Demanda de Energia Elétrica." Relatório da Comissão de Análise do Sistema Hidrotérmico de Energia Elétrica.

Larcom, S., F. Rauch, and T. Willems. 2017. "The benefits of forced experimentation: striking evidence from the London underground network." Q. J. E., 132(4): 2019-2055.

Levinson, A. 2014. "California energy efficiency: Lessons for the rest of the world, or not?" $J$. Econ. Behav. and Organ., 107: 269-289.

Maurer, L., M. Pereira, and J. Rosenblatt. 2005. "Implementing Power Rationing in a Sensible Way: Lessons Learned and International Best Practices.” World Bank Report.

Meier, A. 2005. Saving Electricity in a Hurry. OECD/IEA.

Miller, C. 2016. "The Persistent Effect of Temporary Affirmative Action.” American Econ. J.: Appl. Econ., 9(3): 152-190.

Reiss, P., and M. White. 2008. "What Changes Energy Consumption? Prices and Public Pressures.” RAND J. Econ., 39(3): 636-663.

Sallee, J. 2014. "Rational Inattention and Energy Efficiency.” J. Law and Econ., 57(3): 781-820.

Wolfram, C., O. Shelef, and P. Gertler. 2012. "How Will Energy Demand Develop in the Developing World?" J. Econ. Perspectives, 26: 119-138. 